$$
\text { UNIVERSIDADE DE BRASÍLIA }
$$

FACULDADE DE ECONOMIA, ADMINISTRAÇÃO, CONTABILIDADE E CIÊNCIA DA INFORMAÇÃO E DOCUMENTAÇÃO - FACE PROGRAMA DE PÓS-GRADUAÇÃO EM ADMINISTRAÇÃO - PPGA

\author{
SILVIA REGINA VETTORAZZO
}

\title{
INOVAÇÃO EM SERVIÇOS: O CASO DA INTEGRAÇÃO DA CONTA ÚNICA COM O SISTEMA DE PAGAMENTOS BRASILEIRO (SPB)
}




\title{
INOVAÇÃO EM SERVIÇOS: O CASO DA INTEGRAÇÃO DA CONTA ÚNICA COM O SISTEMA DE PAGAMENTOS BRASILEIRO (SPB)
}

\begin{abstract}
Monografia apresentada ao Programa de PósGraduação em Administração (PPGA) da Faculdade de Economia, Administração, Contabilidade e Ciências da Informação e Documentação (FACE), da Universidade de Brasília, como requisito parcial à obtenção do grau de Especialista em Orçamento e Finanças.
\end{abstract}

Orientador: Prof. Dr. Eduardo Raupp de Vargas

Brasília - DF 


\section{INOVAÇÃO EM SERVIÇOS: O CASO DA INTEGRAÇÃO DA CONTA ÚNICA COM O SISTEMA DE PAGAMENTOS BRASILEIRO (SPB)}

Brasília, junho de 2009

Monografia aprovada por:

Eduardo Raupp de Vargas, Dr. (Orientador)

Universidade de Brasília, Programa de Pós-Graduação em Administração 
Ao meu marido Paulo Henrique, pelo seu grande incentivo, dedicação e amor incondicional, que recompensam todo meu esforço e traz vida à minha vida.

Aos meus pais, que me ensinaram a importância do estudo e, mesmo longe, estão sempre ao meu lado. 


\title{
AGRADECIMENTOS
}

\author{
Ao orientador Eduardo Raupp, por seu apoio e pelos ensinamentos que \\ possibilitaram a elaboração deste trabalho.
}

Ao meu marido, pela compreensão dos momentos ausentes e incentivos em todos os momentos.

A minha família e amigos, por entenderem minhas ausências.

Aos meus amigos, especialmente o Fernando Travassos, pela contribuição com sugestões e com a revisão desta monografia.

Ao meu amigo Luizinho, que foi meu companheiro durante o curso, por seu apoio e sua paciência.

Aos meus colegas de trabalho, que contribuíram para a realização da pesquisa.

À minha amiga Miyuki, pelo incentivo e por ser responsável direta pela minha participação neste curso.

Às minhas chefias, pela compreensão nos momentos de ansiedade, principalmente na elaboração desta monografia.

E, por fim, aos professores e colegas de curso, que ajudaram a manter o clima agradável e propício à aprendizagem. 


\section{RESUMO}

Este estudo investiga o fenômeno da inovação em serviços no setor público, com objetivo de identificar se a solução de Tecnologia da Informação e Comunicação (TIC) responsável pela integração da Conta Única do Tesouro Nacional com o Sistema de Pagamentos Brasileiro (SPB) pode ser considerada um serviço inovador. Com base na literatura científica pertinente ao tema, são apresentados e discutidos os conceitos e constructos teóricos referentes à inovação em serviços, com destaque para a abordagem tecnicista e para os serviços baseados em conhecimento; a inovação no setor público; e a integração da Conta Única com o SPB. O estudo foi desenvolvido tendo como base um estudo de caso, qualitativo e de natureza descritiva, evidenciado por meio de pesquisa documental e entrevistas, a partir da construção de um modelo de análise baseado na literatura estudada, que propôs duas categorizações - o potencial de inovação do projeto SOTN e a Inovação tecnológica no serviço SOTN. Em relação ao potencial de inovação do projeto SOTN, pode-se observar que as características/atributos de práticas inovadoras para o setor público identificadas por Klering e Andrade (2006) são adequadas para avaliar o potencial de inovação de um projeto que implementa uma solução de TIC baseada em sistemas de informação, como é o caso da integração da Conta Única com o SPB. Conforme a análise dos resultados, o potencial de inovação do projeto SOTN atende as características/atributos: introdução de mudanças, qualitativas e quantitativas, em relação a práticas anteriores; accountability; transferibilidade; e incorporação de tecnologias facilitadoras da ação pública, e atende parcialmente a característica/atributo: ampliação do número de beneficiários. Em relação à inovação tecnológica no serviço SOTN, pode-se observar que o modelo do ciclo reverso do produto proposto por Barras (1986) pode ser utilizado para situar a inovação em uma solução de TIC baseada em sistemas de informação, como é o caso da integração da Conta Única com o SPB. A análise dos resultados enquadra o SOTN nas segunda e terceira fases do ciclo reverso do produto.

Palavras-chave: Inovação em serviços; Inovação no Setor público; Inovação em serviços baseados em Tecnologia da Informação e Comunicação 


\section{LISTA DE QUADROS}

Quadro 1 - llustração das fases do ciclo reverso do produto em aplicação com computador. 18

Quadro 2 - Conjunto de características ou atributos presentes num projeto inovador. 24

Quadro 3 - Benefícios do SOTN em relação ao SPB mainframe...... 31

Quadro 4 - Instrumento de coleta para os objetivos específicos 37

Quadro 5 - Características/atributos não selecionados. 39

Quadro 6 - Conjunto de características/atributos que permitem identificar se o projeto SOTN é inovador. .39

Quadro 7 - Princípios da EGTI com os Direcionamentos Estratégicos do SERPRO. .44

Quadro 8 - Atendimento das características/atributos pelo projeto SOTN .52 


\section{LISTA DE SIGLAS}

BACEN - Banco Central do Brasil

DARF - Documento de Arrecadação Federal

DPF - Departamento de Polícia Federal

EAP - Estrutura Analítica do Projeto

e-Car - Sistema para Controle, Acompanhamento e Avaliação de Resultados

e-Gov - Governo Eletrônico

EGTI - Estratégia Geral de Tecnologia da Informação

GPC - Programa de Gestão Pública e Cidadania

GPS - Guia da Previdência Social

GRU - Guia de Recolhimento da União

ITIL - Information Technology Infrastructure Library

Kibs - Knowledge Intensive Business Services

PDA - Personal Digital Assistant

PDTI - Plano Diretor de Tecnologia da Informação

PIB - Produto Interno Bruto

PSDS - Processo SERPRO de Desenvolvimento de Soluções do SERPRO

PSGP - Programa SERPRO de Gerenciamento de Projetos

PSGTI - Programa SERPRO de Gerenciamento de Serviços de Tecnologia da

Informação e Comunicação

PSS - Programa SERPRO de Segurança

RSFN - Rede do Sistema Financeiro Nacional

SIAFI - Sistema Integrado de Administração Financeira do Governo Federal

SIC - Serviços Intensivos em Conhecimento

SOTN - Sistema de Operações do Tesouro Nacional

SPB - Sistema de Pagamentos Brasileiro

SERPRO - Serviço Federal de Processamento de Dados

SSP01 - Requisitos Não-Funcionais do Piloto SOTN

SSP04 - Documento de Solução da Arquitetura - DAS do Piloto SOTN

SSP05 - Ambientes de Produção da Solução Piloto SOTN

SSP12 - Testes de Tecnologia da Solução Piloto SOTN

STN - Secretaria do Tesouro Nacional 
STR - Sistema de Transferência de Reservas

SUNAF - Superintendência de Relacionamento com Clientes - Administração

Financeira

TIC - Tecnologia da Informação e Comunicação 


\section{SUMÁRIO}

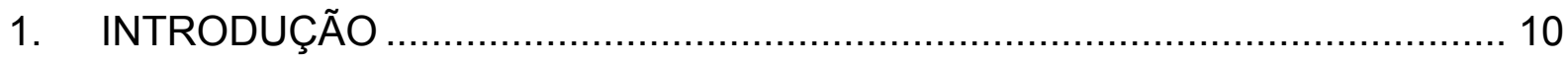

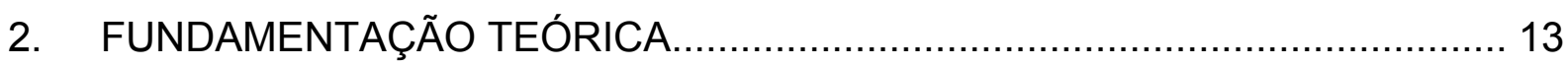

2.1. Inovação em serviços ..................................................................... 13

2.1.1. Influência da tecnologia da informação na inovação em serviços e

o modelo do ciclo reverso do produto .................................................... 15

2.1.2. O papel das empresas de serviços intensivos em conhecimento. 19

2.2. Inovação no setor público brasileiro...................................................... 22

2.3. Integração entre a Conta Única e o SPB .............................................. 28

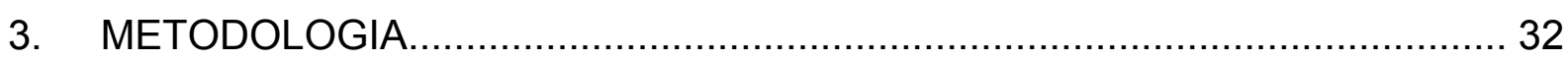

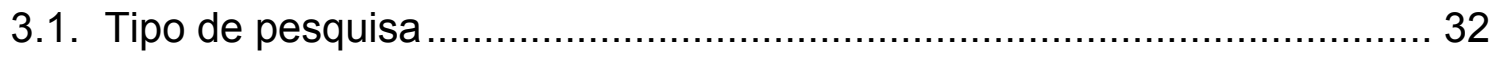

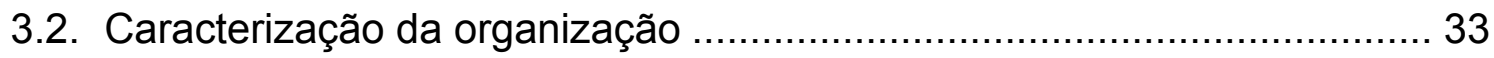

3.3. Participantes da pesquisa e amostra de documentos ............................ 34

3.4. Instrumento da coleta de dados ....................................................... 35

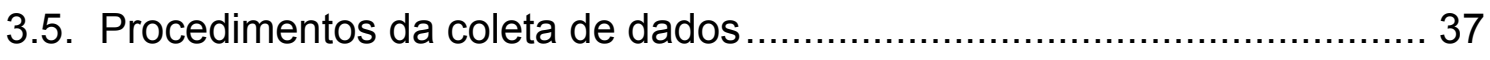

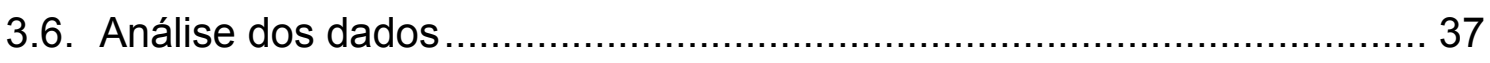

3.6.1. Potencial de inovação do projeto SOTN …………………….... 38

3.6.2. Inovação tecnológica em serviços para o SOTN ........................... 40

4. APRESENTAÇÃO E ANÁLISE DOS RESULTADOS ..................................... 41

4.1. Potencial de inovação do Projeto SOTN................................................. 41

4.1.1. Introdução de mudanças, qualitativas e quantitativas, em relação a

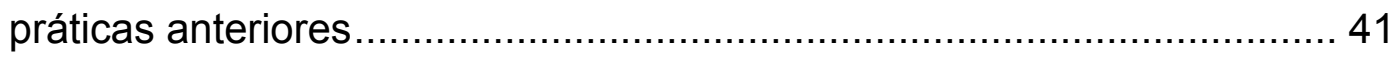

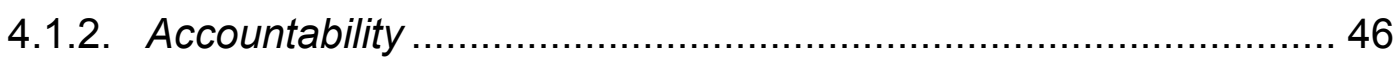

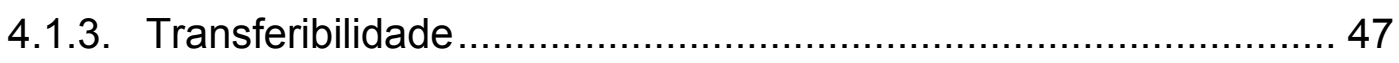

4.1.4. Ampliação do número de beneficiários ...................................... 49

4.1.5. Incorporação de tecnologias facilitadoras da ação pública............ 51

4.1.6. Visão geral do potencial de inovação do projeto SOTN................ 52

4.2. Inovação tecnológica em serviços para o SOTN ....................................... 52

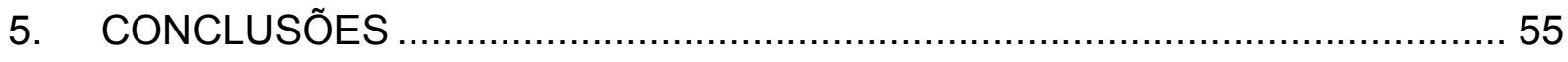

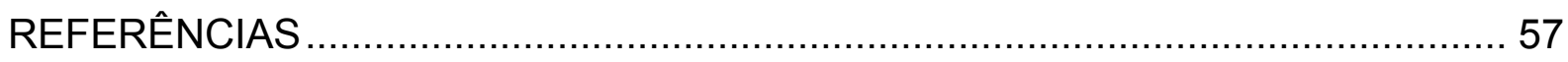

APÊNDICE A - Roteiro de entrevista semi-estruturada .......................................... 61 


\section{INTRODUÇÃO}

O setor de serviços se destaca dentre as atividades produtivas da economia brasileira e, também, na economia mundial, principalmente nos países desenvolvidos. Este fato pode ser observado pelo volume de faturamento angariado no setor, bem como pela capacidade de geração de empregos (GALLOUJ, 2007). Esta importância fez com que estudos e pesquisas acerca da inovação em serviços tenham se avolumado recentemente. Em especial, tem se dado destaque ao papel das novas tecnologias, como as da informação e da comunicação, no desenvolvimento de serviços inovadores.

É importante observar que as economias estão cada vez mais baseadas no conhecimento e no aprendizado. Esta constatação fez com que as atenções se voltassem para os serviços empresariais intensivos em conhecimento, os quais apresentam um importante potencial de inovação e são fundamentais para a produção de bens de alta tecnologia. Empresas que requerem soluções específicas necessitam ter acesso à competência das empresas baseadas em conhecimento.

Neste cenário enquadra-se o Serviço Federal de Processamento de Dados (SERPRO). O SERPRO é uma empresa pública de prestação de serviços altamente especializada. Foi criado com o objetivo de modernizar e dar agilidade a setores estratégicos da Administração Pública brasileira.

O maior cliente do SERPRO é o Ministério da Fazenda. Os principais serviços, baseados em Tecnologia da Informação e Comunicação (TIC), utilizados por este órgão foram desenvolvidos pelo SERPRO.

Nos últimos 20 anos o Brasil passou por uma profunda reforma na área de finanças públicas, compreendendo reformas estruturais, institucionais, legais e organizacionais. Faz parte dessas mudanças a criação da Secretaria do Tesouro Nacional (STN) que integra o Ministério da Fazenda, a implantação do Sistema Integrado de Administração Financeira do Governo Federal (SIAFI) desenvolvido pelo SERPRO e a criação a Conta Única do Tesouro Nacional, mantida no Banco Central do Brasil.

Segundo Albuquerque, Medeiros e Feijó (2008), antes da criação da Conta Única cada unidade administrativa do governo abria suas próprias contas bancárias e usualmente controlava determinados recursos mediante abertura de contas específicas. A efetiva implementação de adequado mecanismo de controle das 
disponibilidades financeiras de diversas unidades administrativas do Governo Federal somente foi possível com a implementação da Conta Única, no âmbito do SIAFI, o que propiciou as condições para eliminar as contas correntes mantidas na rede bancária. Deste modo, todos os recursos financeiros disponíveis de todas as entidades do governo central passaram a ser depositados na Conta Única.

Em 2002, o SERPRO implantou uma nova funcionalidade no SIAFI que permitiu a integração do sistema da Conta Única com o Sistema de Pagamentos Brasileiro (SPB), ainda, que de forma parcial. Esta integração possibilitou que as instituições financeiras, que realizam operações com o Tesouro, repassem, em tempo real, os recursos para a Conta Única com contabilização automática na Unidade Gestora responsável. Antes, as operações de débito e crédito na Conta Única eram realizadas através de agentes financeiros e, com a integração, essas operações podem ser realizadas sem intermediários.

Seguindo esta trajetória, o SERPRO desenvolveu o Sistema de Operações do Tesouro Nacional (SOTN). O principal objetivo do SOTN é tornar disponível uma solução que permita à STN atuar, de forma autônoma, como participante e provedor de serviços do SPB, assumindo funções que hoje o Banco Central do Brasil realiza para o Tesouro Nacional. Esta solução envolve e complementa a implantada em 2002.

Diante deste contexto, surgiu a necessidade de investigar o seguinte problema de pesquisa: Como identificar se a solução de TIC responsável pela integração da Conta Única com o SPB pode ser considerada um serviço inovador?

Para responder a esta questão, a pesquisa tem por objetivo geral identificar se a solução de TIC, denominada SOTN, responsável pela integração da Conta Única com o SPB pode ser considerada um serviço inovador.

Os objetivos específicos da pesquisa que permitiram alcançar o objetivo geral foram:

- Discutir conceitos de inovação em serviços;

- $\quad$ Discutir conceitos de inovação no setor público;

- $\quad$ Analisar a integração entre a Conta Única e o SPB;

- Definir um modelo de análise para identificar se a solução de TIC responsável pela integração da Conta Única com o SPB pode ser considerada um serviço inovador; 
- Identificar a inovação em uma solução de TIC a partir da solução de integração da Conta Única com o SPB.

Este estudo está assim distribuído. O capítulo 1 introduz a contextualização do problema de pesquisa e os objetivos de pesquisa, ressaltando a relevância e justificativa de propósitos. Em seguida, o capítulo 2 apresenta a discussão sobre a inovação em serviços, a inovação no setor público brasileiro e a integração entre a Conta Única e o SPB. O capítulo 3 relata a metodologia utilizada, propondo um modelo de análise de conteúdo para as informações obtidas. O capítulo 4 apresenta e analisa os resultados da pesquisa realizada. Por fim, são apresentadas as conclusões deste estudo. 


\section{FUNDAMENTAÇÃO TEÓRICA}

Neste capítulo são discutidos os conceitos e constructos teóricos referentes ao tema apresentado neste estudo. Inicialmente, são discutidos os conceitos de inovação em serviços, suas características e abordagens, com maior detalhamento da abordagem tecnicista a partir do entendimento da influência da tecnologia da informação na inovação em serviços e, em especial, nos serviços baseados em conhecimento. Na seqüência discutem-se os conceitos de inovação no setor público, como forma de analisar as especificidades da inovação em serviços quando o provedor de serviços é um órgão público. Por fim, é analisada a integração entre a Conta Única do Tesouro Nacional e o SPB, apresentando conceitos da Conta Única do Tesouro Nacional, do SPB e dos sistemas de informação do Tesouro Nacional responsáveis por esta integração. Esta revisão conceitual sobre o SPB é fundamental para que se possa atingir o objetivo proposto neste trabalho de identificar a inovação em serviços de TIC a partir da solução de integração com a Conta Única.

\subsection{INOVAÇÃO EM SERVIÇOS}

O setor de serviços vem se destacando na economia mundial. Os principais fatores que contribuíram para este fenômeno são: a geração de empregos e o valor de faturamento deste setor. Conforme Gallouj (2007), os serviços representam mais de $70 \%$ da riqueza e do emprego na maioria dos países desenvolvidos. No Brasil, segundo o Instituto Brasileiro de Geografia e Estatística (2008), em 2007, o setor de serviços representou $56,5 \%$ do Produto Interno Bruto (PIB) nacional medido a preços de mercado.

Para Freire (2006), o que fez crescer a demanda por serviços foi a flexibilização de processos produtivos e de mercado que aumentou a complexidade dos ambientes externos e internos das empresas.

\footnotetext{
A partir dos anos 1970, a crescente divisão técnica do trabalho, a progressiva concentração de capital, a expansão de mercados, o desenvolvimento das tecnologias da informação, as mudanças no ambiente institucional (regulação, competitividade e estrutura de gestão), entre outros fatores, contribuíram para um contexto de expansão das atividades de serviços (FREIRE, 2006, p.108).
}

Inovar significa tornar novo; renovação (FERREIRA, 1986). Inovação pode ser definida, segundo Pavitt (1984), como um produto ou processo produtivo - novo ou 
melhor - usado ou comercializado com sucesso. Vargas (2007) considera que a inovação representa a possibilidade de um desenvolvimento diferenciado e, especificamente, responde por aumentos na produtividade e pela oportunidade de novos patamares de vantagem competitiva.

Vargas (2007) sustenta que a teoria da inovação é originária da análise da indústria manufatureira, e mantém em suas análises a herança do modelo fordista em relação à preponderância da indústria sobre os serviços. Sendo assim, os primeiros trabalhos voltados às especificidades do processo de inovação em serviços resultaram de análises da difusão de inovações tecnológicas, principalmente de tecnologias da informação e da comunicação, oriundas da indústria no setor de serviços.

Vargas e Zawislak (2006) discutem as controvérsias que marcam o debate teórico acerca da inovação em serviços.

\begin{abstract}
O debate teórico acerca da inovação em serviços é bastante novo e controverso. Por um lado, autores debatem se o setor de serviços possui a capacidade de gerar inovações endogenamente, ou, ao contrário, se as mudanças verificadas são subprodutos de processos de inovação originários da indústria. Por outro lado, onde esta discussão se encontra superada, emerge um segundo ponto: a conveniência de uma teoria específica para a inovação em serviços. Ou seja, considerando que as organizações do setor de serviços inovam, em que medida este processo guarda especificidades em relação ao verificado na manufatura, e que, portanto, merecem uma explicação diferenciada (VARGAS; ZAWISLAK, 2006).
\end{abstract}

As diferentes respostas aos questionamentos relatados no parágrafo anterior podem ser agrupadas em três abordagens principais, conforme Vargas (2007):

- A abordagem tecnicista

Esta abordagem está baseada na concepção de que a inovação em serviços resulta da adoção de inovações tecnológicas desenvolvidas no setor industrial, em especial no setor de produção de bens de capital. Esse enfoque está fortemente associado à análise das mudanças provocadas pelo processo de informatização em vários serviços, como, por exemplo, a adoção de caixas eletrônicas, no caso dos serviços bancários, e da adoção das chamadas tecnologias da informação. A principal tentativa de sistematização dessa abordagem é o modelo do ciclo reverso do produto proposto por Barras (1986);

- A abordagem baseada nos serviços 
Procura centrar sua análise no que define como trajetórias intangiveis dos serviços, relacionando-as com modalidades específicas de inovação nesse setor. A idéia central desse enfoque é que a relação usuários-produtor, mesmo considerando variações em seu grau de intensidade de acordo com o ramo dos serviços considerado, oferece oportunidades para a inovação na elaboração do serviço, incluindo produção e processo, que supera qualquer inovação tecnológica de processo ou de produto;

- A abordagem integradora

Esse enfoque se propõe a reconciliar bens e serviços, integrando-os definitivamente em uma única teoria da inovação. Mesmo ressaltando as especificidades dos serviços, a abordagem integradora considera que a inovação envolve características genéricas, cuja ênfase recairá sobre peculiaridades da manufatura ou dos serviços, de acordo com a intensidade da relação usuário-produtor verificada no mercado específico em análise.

\subsubsection{INFLUÊNCIA DA TECNOLOGIA DA INFORMAÇÃO NA INOVAÇÃO EM SERVIÇOS E O MODELO DO CICLO REVERSO DO PRODUTO}

Considerando o objetivo geral deste trabalho, vinculado à investigação da possibilidade de geração de novos serviços pela integração da Conta única e SPB, isto é, novos serviços oriundos da aplicação de tecnologias da informação, passamos a examinar, em maior detalhe, o modelo do ciclo reverso do produto (BARRAS, 1986), integrante da chamada abordagem tecnicista da inovação em serviços. Este modelo mostra-se adequado, justamente, para analisar a influência das tecnologias da informação e da comunicação na evolução dos serviços (VARGAS; ZAWISLAK, 2005).

Constatam Hamdani e Fossey (2007) que as novas tecnologias tiveram papel importante em moldar os serviços como inovadores e produtores de tecnologia porque elas se adaptaram aos serviços muito mais do que as tecnologias do passado e também porque as indústrias de serviços são intensivas no tipo de capital necessário à sua produção. Hamdani e Fossey (2007) afirmam, ainda, que a principal motivação para a busca por novas tecnologias foi a própria iniciativa das empresas de serviços, influenciadas pela necessidade de enfrentar a crescente competição e os mercados globalizados de serviços. Assim, a proliferação das TIC juntamente com o reconhecimento do conhecimento como vantagem estratégica têm sido pivô da transformação dos serviços em vanguarda da inovação (HAMDANI; FOSSEY, 2007). 
Segundo Trindade e Segre (1995), uma forma tradicional de explicar a inovação tecnológica e sua difusão é colocá-la como uma decorrência da pressão da demanda. No entanto, tal modelo não é suficiente para explicar como as novas tecnologias, originárias do setor de bens de capital, são aplicadas no setor de serviços. O entendimento desse processo de transmissão requer um modelo mais completo que leve em consideração o suprimento de uma nova tecnologia pelos produtores e a demanda por essa tecnologia pelos usuários. Compreender bem essa passagem auxilia no entendimento das dinâmicas próprias dos setores, no que diz respeito às diferentes taxas de inovação alcançadas pelo setor de bens de capital (produtor) e pelos setores de bens de consumo (usuário).

Para Vargas e Zawislak (2005), o enfoque tecnicista, sobretudo por meio do modelo do "ciclo reverso do produto", mostrou-se adequado para uma análise de difusão tecnológica nas empresas de serviços.

O modelo do ciclo reverso do produto foi proposto por Barras (1986) como um modelo teórico sobre a inovação em indústrias de serviços. Embora Barras (1986) vislumbrasse uma teoria geral sobre a inovação em serviços, seu modelo foi concebido e aplicado empiricamente em determinados ramos dos serviços, notadamente naqueles baseados em tecnologias da informação e comunicação. O modelo de ciclo de vida proposto por Barras (1986) é espelhado no ciclo normal do produto. A teoria do ciclo normal do produto é sobre a inovação aplicada ao setor de produção de bens de capital que adotam novas tecnologias como a tecnologia de informação (BARRAS, 1986).

Barras (1986) descreve três fases para o modelo do ciclo normal do produto:

- A primeira fase é a de introdução. Corresponde a um período de grande inovação do produto com o estabelecimento de novas indústrias. É caracterizada por um rápido avanço tecnológico e pela diversidade de novos produtos. É utilizado o desempenho do produto para capturar novos mercados;

- A segunda fase é a de crescimento. A ênfase passa a ser na melhoria da qualidade de uma decrescente oferta de produtos. Os métodos de produção se tornam mais padronizados e automatizados com o aumento da intensidade de capital e dos volumes de produção que crescem à medida que os mercados se expandem; 
- A terceira fase é a de maturidade. Aumenta a ênfase nas melhorias incrementais de processos a fim de reduzir os custos unitários de poucos produtos padronizados, em um mercado perto da saturação. Os métodos de produção alcançam o máximo de automação, com maior concentração em unidades de produção e com investimento em redução de mão-de-obra.

Segue-se, ainda, uma quarta fase em que o ciclo recomeça após o alcance da maturidade. Esse novo ciclo é necessário, pois as indústrias já estabelecidas que produzem os bens de capital, tornam-se cada vez mais vulneráveis à concorrência de novas e mais avançadas tecnologias.

No modelo do ciclo reverso do produto, Barras (1986) também define três fases que compõem o ciclo de inovação nos serviços, porém no sentido inverso em termos de grau de novidade das inovações e, portanto, de seu impacto:

- Na primeira fase as aplicações de novas tecnologias resultam em aumento da eficiência da entrega dos serviços existentes. Nesta fase, as organizações adotantes da tecnologia se concentram em aplicá-la na inovação incremental dos processos de prestação de serviços, com o objetivo de aprimorar a entrega dos serviços prestados, e, com isso, atingir uma redução significativa nos custos. Como exemplo pode-se recordar, nos anos 70 , as aplicações utilizando tecnologia de grande porte, conhecida por mainframe, em organizações de serviço foram direcionadas para a melhora da eficiência, levando a uma redução na carga de trabalho. Este exemplo pode ser melhor compreendido no Quadro 1;

- Na segunda fase a tecnologia é aplicada para melhorar a qualidade dos serviços. Esta melhora na qualidade encoraja a expansão de mercado. A tecnologia é direcionada para um processo inovativo mais abrangente, buscando mais eficácia do que a eficiência na entrega de serviços e mais incremento na qualidade do que a redução dos custos. Conforme o Quadro 1, esses efeitos podem ser vistos, nos anos 80, nas aplicações de tecnologia de utilizam mini e micros computadores na indústria de serviços. O foco dessas aplicações desloca-se dos sistemas corporativos centralizados para a administração interna para aplicações 
departamentais em máquinas dedicadas visando à melhora de serviço em setores onde há um crescimento da demanda;

- Na terceira fase, a tecnologia ajuda numa mudança radical dos serviços existentes ou gera novos serviços. A inovação do produto predomina em relação à inovação de processo, ainda que este tipo de diferenciação seja bastante complexo em serviços (GALLOUJ, 2007). A ênfase na competição desloca-se para uma diferenciação do produto a fim de abrir e capturar novos mercados. O investimento em novas tecnologias torna-se predominante em relação à aplicação de capital, gerando a redução de capital. O impacto total sobre a produção e emprego é expansionista. Conforme o Quadro 1, esses efeitos podem ser vistos, nos anos 90, nas aplicações de tecnologia que utilizam redes de telecomunicação na indústria de serviços, como exemplo a mudança da infra-estrutura de rede de telecomunicação analógica para digital, com capacidade de transmissão de textos, dados, voz e imagem, tais redes irão prover meios de produção e entrega para uma gama de novos serviços eletrônicos interativos abrindo novos mercados para estes serviços.

\begin{tabular}{|c|c|c|c|}
\hline Fase do Ciclo & $\begin{array}{l}\text { 1. Melhoria da } \\
\text { Eficiência }\end{array}$ & $\begin{array}{l}\text { 2. Melhoria da } \\
\text { Qualidade }\end{array}$ & 3. Novos serviços \\
\hline Período & anos 1970 & anos 1980 & anos 1990 \\
\hline $\begin{array}{l}\text { Tecnologia de Hardware } \\
\text { de Computador }\end{array}$ & Computador de grande porte & $\begin{array}{c}\text { Sistema em tempo real } \\
\text { Mini\&Micros }\end{array}$ & Redes \\
\hline $\begin{array}{l}\text { Setores de Aplicações } \\
\text { a. Seguros }\end{array}$ & $\begin{array}{l}\text { Registro de políticas aplicadas } \\
\text { ao computador }\end{array}$ & Cotação em tempo real & $\begin{array}{c}\text { Todos os serviços disponíveis } \\
\text { em tempo real }\end{array}$ \\
\hline b. Contabilidade & $\begin{array}{c}\text { Auditoria com uso do } \\
\text { computador, } \\
\text { Gravação em Tempo Interno }\end{array}$ & $\begin{array}{l}\text { Gerenciamento com o uso do } \\
\text { computador }\end{array}$ & $\begin{array}{l}\text { Auditoria e contabilidade } \\
\text { totalmente automaizados }\end{array}$ \\
\hline c. Governo local & $\begin{array}{l}\text { Sistemas financeiros } \\
\text { corporativos }\end{array}$ & $\begin{array}{l}\text { entrega de serviços } \\
\text { departamentais }\end{array}$ & $\begin{array}{c}\text { Serviços de Informação } \\
\text { pública }\end{array}$ \\
\hline
\end{tabular}

Quadro 1 - Ilustração das fases do ciclo reverso do produto em aplicação com computador Fonte: Adaptado de Barras (1986, p.166)

A seqüência de fases do ciclo reverso do produto pode ocorrer em paralelo com fases do ciclo normal do produto nas indústrias de bens de capital tais como nas indústrias de computação que produzem a tecnologia, produzindo feedback entre os dois ciclos de inovação. Como exemplo quando a inovação na entrega de serviços cria 
uma nova demanda por desempenho em processamento levando a uma inovação secundária no design de novos processadores.

Conforme afirmação de Vargas e Zawislak (2005), o modelo do ciclo reverso do produto mostrou-se adequado para uma análise de difusão tecnológica nas empresas de serviços. Para Gallouj (2007), este estudo na geração de inovação nos serviços conduzido por Barras mostra que o ciclo de inovação é o inverso ao ciclo normal do produto, pois as ondas de informatização (computador de grande porte, mini e microinformática e redes) que originam o ciclo de inovação nos serviços articula sucessivamente uma fase de inovação do processo incremental, uma fase de inovação do processo radical e uma fase de inovação do produto. A inovação não reside nesses sistemas técnicos em si, mas nas mudanças que eles possibilitam por meio de toda a gama do espectro dos processos de aprendizagem (GALLOUJ, 2007).

\subsubsection{O PAPEL DAS EMPRESAS DE SERVIÇOS INTENSIVOS EM CONHECIMENTO}

Segundo Bernardes e Kallup (2007), desde o pós-guerra, com o reconhecimento do progresso tecnológico como força motriz do crescimento econômico, as agências governamentais e organizações multilaterais têm mobilizado grandes esforços para construir metodologias capazes de mensurar a nova dinâmica e a natureza da mudança tecnológica nas economias hegemônicas. Neste sentido, as evidências sinalizam para a ocorrência de dois fenômenos nas economias contemporâneas. Simultaneamente à constatação de que as economias estão cada vez mais baseadas no conhecimento e no aprendizado proporcionado pela integração social, verifica-se o aumento da participação dos setores de serviços na atividade da economia mundial - conforme mencionado no item 2.1 - e nas trajetórias de inovações empresariais.

Enquanto as tecnologias da informação e da comunicação inicialmente forneceram o ímpeto para a inovação, outros ramos de atividade, muitos diferentes daqueles que definem o ciclo reverso do produto, começaram a chamar mais atenção (HAMDANI; FOSSEY, 2007). Essas empresas de serviços são classificadas como Knowledge Intensive Business Services (Kibs), ou seja, serviços empresariais intensivos em conhecimento, tais como as empresas de informática, de telecomunicação, de consultoria, de pesquisa e desenvolvimento (BERNARDES; 
KALLUP, 2007). No Brasil estas empresas são conhecidas como Serviços Intensivos em Conhecimento (SIC) (FREIRE, 2006).

Afirma Freire (2006) que pelo fato de atuarem como difusores de conhecimento e pelo seu enredamento vasto na cadeia produtiva, os SIC podem representar uma tendência analítica promissora, especialmente em um momento em que atores públicos têm pensado políticas de desenvolvimento de escopo transversal, nas quais a inovação é vista como elemento central. Neste contexto, Kubota (2006) considera que uma crescente corrente da literatura está interessada em investigar o papel dos SIC enquanto indutoras do processo de inovação em empresas, inclusive em outros setores que não o de serviços.

Freire (2006) informa, ainda, que os SIC caracterizam-se por: i) ter participação expressiva em valor adicionado; ii) utilizar recursos humanos de mais alta qualificação comparado a outros setores da economia (maior número de técnicos em geral, engenheiros, cientistas, administradores, economistas etc.); iii) atuar como fontes primárias de informação e de conhecimentos, fornecer tecnologia de informação e auxiliar processos de inovação (são empresas que tendem a contribuir para os sistemas nacionais de inovação, remodelando processos de produção e de gestão, tanto em serviços como em outros setores); iv) proporcionar alta interação produtor usuário.

No Brasil, Bernardes e Kallup (2007) realizaram um estudo para mensurar a participação de atividades classificadas como SIC na estrutura da "economia de serviços". Este estudo aponta para a existência e o desenvolvimento de uma economia de serviços baseados em conhecimento - dinâmica e complexa - ainda que relativamente incipiente e fortemente concentrada regionalmente. Como ilustrado na Figura 1, estes autores demonstram que SIC contribuem com uma parcela relevante na atividade econômica e comercial. 


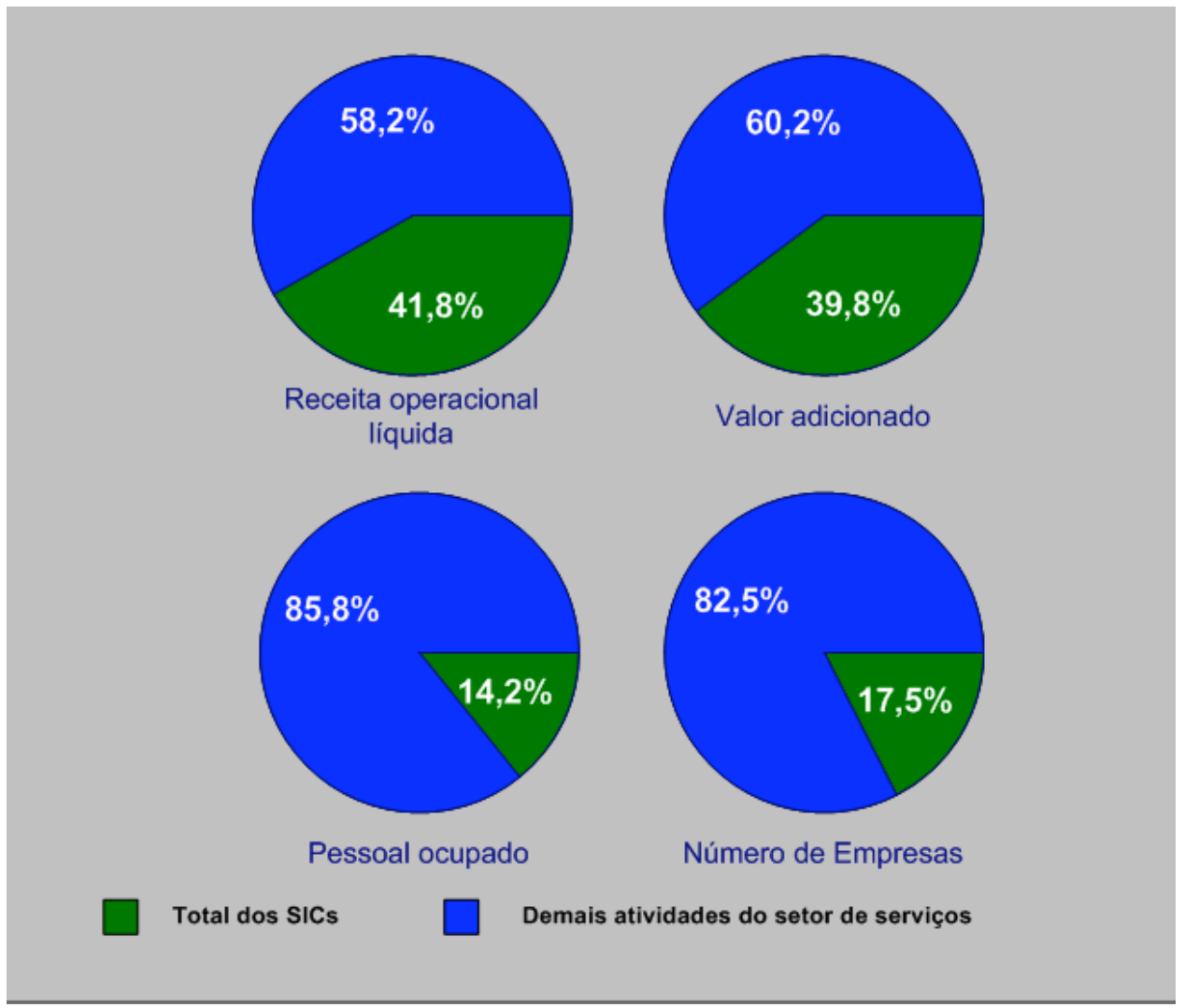

Figura 1 - Composição do setor de serviços da economia brasileira, segundo atividades classificadas em SIC e demais atividades do setor (Brasil, 2001)

Fonte: Bernardes e Kallup (2007, p. 137)

A partir do exposto neste item, pode-se observar que as economias estão cada vez mais baseadas no conhecimento e no aprendizado. Esta constatação fez com que as atenções se voltassem para os serviços empresariais intensivos em conhecimento os quais apresentam um importante potencial de inovação e são fundamentais para a produção de bens de alta tecnologia. Empresas que requerem soluções específicas necessitam ter acesso à competência das empresas baseadas em conhecimento. Freire (2006) afirma que o estímulo ao SIC pode ser um vínculo interessante para futuras políticas públicas e Kon (2007) acrescenta que o planejamento de políticas públicas com vistas ao desenvolvimento econômico deve priorizar medidas específicas para apoio ao fornecimento de uma infra-estrutura baseada no conhecimento.

As observações apresentadas no parágrafo anterior sugerem uma outra questão relevante que é a inovação especificamente no setor público, a ser discutida no próximo item. 


\subsection{INOVAÇÃO NO SETOR PÚBLICO BRASILEIRO}

Segundo Kettl (2005), desde os primeiros anos da década de 80, vê-se crescer em todo o mundo uma onda global de reforma do setor público. Praticamente todos os governos têm empreendido esforços para modernizar a administração pública.

No Brasil, várias tentativas de reformas foram introduzidas desde 1930, sendo a mais recente a reforma da administração pública proposta em 1995 pelo governo Fernando Henrique Cardoso, tendo em vista a necessidade de melhoria e eficiência nos serviços públicos. A reforma de 1995 foi baseada nos princípios da chamada administração pública gerencial que, para Bresser Pereira (2005), é orientada para o cidadão e para a obtenção de resultados; pressupõe que os políticos e os funcionários públicos são merecedores de grau limitado de confiança; como estratégia serve-se da descentralização e do incentivo à criatividade e à inovação; e utiliza o contrato de gestão como instrumento de controle dos gestores públicos.

Desde então, a busca pelo entendimento da dinâmica da inovação nos serviços públicos brasileiros ganhou espaço nos debates acadêmicos e governamentais. Farah (2006) aborda os diferentes significados atribuídos ao termo inovação.

\footnotetext{
Hoje, cerca de 20 anos após a incorporação pioneira do termo inovação às discussões sobre a administração pública brasileira, 0 uso da expressão inovação se difundiu, estando presente em toda e qualquer referência à gestão pública e aos desafios que esta deve enfrentar. Na utilização contemporânea do termo inovação, por sua vez, distintos significados lhe são atribuídos: de um lado, inovar significa adotar ou implantar processos eficientes de gestão; de outro, inovar significa democratizar a ação estatal, tanto do ponto de vista da ampliação da parcela da população com acesso a serviços públicos, quanto da perspectiva dos processos de formulação, implementação e controle das políticas públicas (FARAH, 2006, p.50).
}

Para Klering e Andrade (2006), inovar no setor público é efetivamente desenvolver uma condição nova em seus pressupostos e nas suas ações. Não basta apenas mudar, ou propor "novas" reformas, sem trazer uma transformação significativa no processo de definição e implementação de políticas públicas, no qual problemas brasileiros, como, por exemplo, a exclusão social, devem ter um foco prioritário. Também, sugerem os autores, não basta reformar o aparelho estatal sem compreender que a gestão deve estar mais próxima de uma visão de gerenciamento participativo. Assim, compreender a mudança no setor público, dentro de uma perspectiva 
transformadora, significa entendê-la a partir do sentido explícito e necessário de inovação.

No mundo contemporâneo, as mudanças e inovações têm grande importância na transformação e melhoria da qualidade de vida de pessoas, grupos e povos, que caminham buscando os ideais de crescente desenvolvimento, com maior justiça, oportunidades, liberdade e felicidade. Tais idéias podem ser atingidas de forma mais ou menos rápida, dependendo das concepções e das práticas gerenciais colocadas em ação. (KLERING; ANDRADE, 2006).

Segundo Klering e Andrade (2006), na literatura gerencial, os conceitos de mudança e inovação são similares. A busca de mudanças e inovações, rompendo as tradições, pode ser feita de forma mais ou menos eficaz. As mudanças alteram, criam ou ampliam práticas, valores e pressupostos. As inovações constituem mudanças mais radicais e revolucionárias, que trazem e impõem novos paradigmas e arquétipos de ação, abrangendo diferentes áreas ou perspectivas: estratégicas, estruturais, tecnológicas, culturais, humanas, políticas, e de controle. Tais alterações, geralmente de ampliação do setor público, podem ocorrer no nível organizacional ou institucional, em que valores mais sociais passam a ser consolidados.

Para Klering e Andrade (2006), uma prática administrativa, numa organização de qualquer setor e área, tende a carregar um conjunto de características, capazes de impor certas mudanças, de diferentes graus de intensidade. No setor público, uma organização pode ser usada, de forma consciente ou não, para gerar mudanças e inovações. A importância de uma prática inovadora decorre da qualidade das características (ou atributos) que carrega e que geram mudanças e inovações na organização e seu contexto de atuação, que por sua vez geram transformações no respectivo meio social. A posse de atributos confere mais ou menos valor a uma inovação. Para avaliar o valor potencial de um projeto inovador, na transformação de uma sociedade, e desta forma obter uma relação custo-benefício favorável, é apresentado no Quadro 2 um conjunto de características ou atributos, que podem estar presentes num projeto. Tal lista de atributos permite a um gestor checar que atributos estão presentes num projeto e, desta forma, avaliar a qualidade, validade e importância de um projeto público ou social. 


\begin{tabular}{|c|c|}
\hline Características/Atributos & Descrição \\
\hline $\begin{array}{l}\text { Introdução de mudanças, } \\
\text { qualitativas e quantitativas, em } \\
\text { relação a práticas anteriores }\end{array}$ & $\begin{array}{l}\text { Introduzir novos modos ou modelos de provisão de bens e serviços, } \\
\text { ser capaz de mudar hábitos ou costumes de trabalho, desenvolver } \\
\text { produtos e serviços, tanto novos, quanto renovar antigos }\end{array}$ \\
\hline $\begin{array}{l}\text { Melhoria da qualidade de vida do } \\
\text { público-alvo }\end{array}$ & $\begin{array}{l}\text { Ser capaz de gerar fontes de renda, ou melhorar a habitação, } \\
\text { saneamento, saúde, educação do público-alvo; aumentar os } \\
\text { cuidados com o meio ambiente, as relações com as comunidades, } \\
\text { a segurança, a liberdade de expressão, a auto-estima dos cidadãos }\end{array}$ \\
\hline Auto-sustentabilidade & $\begin{array}{l}\text { Ser capaz de vir a sustentar-se de forma própria e autônoma, tendo } \\
\text { em vista seu enfoque no desenvolvimento das pessoas e } \\
\text { instituições envolvidas, evitando práticas paternalistas }\end{array}$ \\
\hline $\begin{array}{l}\text { Viabilidade técnica, gerencial, } \\
\text { econômica e financeira }\end{array}$ & $\begin{array}{l}\text { Ser exeqüível em termos técnicos, gerenciais, econômicos e } \\
\text { financeiros, ou seja, dispor de tecnologia e recursos suficientes e } \\
\text { adequados para a sua implementação, e proporcionar adequada } \\
\text { relação custo-benefício }\end{array}$ \\
\hline Credibilidade pública & $\begin{array}{l}\text { Merecer das instituições envolvidas na sua implantação suficiente } \\
\text { importância e visibilidade interna, e oferecer pronta resposta a } \\
\text { demandas do público-alvo }\end{array}$ \\
\hline Accountability & $\begin{array}{l}\text { Ter suas contas e seu funcionamento apresentados de forma clara, } \\
\text { objetiva e transparente aos seus apoiadores e à sociedade em } \\
\text { geral, com prestações regulares de contas }\end{array}$ \\
\hline $\begin{array}{l}\text { Desenvolvimento de tecnologia e } \\
\text { responsabilidade na utilização de } \\
\text { recursos e oportunidades }\end{array}$ & $\begin{array}{l}\text { Melhorar a gestão de recursos sociais, criando novas tecnologias, } \\
\text { desenvolvendo novas habilidades de ação, dentro de critérios de } \\
\text { ética, correção e justiça }\end{array}$ \\
\hline $\begin{array}{l}\text { Consolidação e ampliação do } \\
\text { diálogo com a sociedade civil }\end{array}$ & $\begin{array}{l}\text { Melhorar a comunicação, interação e envolvimento de uma } \\
\text { comunidade, em relação a assuntos de seu interesse, criando uma } \\
\text { maior "massa crítica" e consciência social, assim como maior } \\
\text { responsabilidade pela coisa pública }\end{array}$ \\
\hline $\begin{array}{l}\text { Articulação com diferentes setores } \\
\text { sociais }\end{array}$ & $\begin{array}{l}\text { Melhorar a comunicação, interação e envolvimento entre os } \\
\text { diferentes setores e atores sociais: o setor público, o setor privado e } \\
\text { o chamado "terceiro setor", em relação a demandas e assuntos de } \\
\text { interesse real e potencial da sociedade, criando maior } \\
\text { responsabilidade e solidariedade social, formulando e } \\
\text { implementando soluções, principalmente via rede de ações }\end{array}$ \\
\hline $\begin{array}{l}\text { Articulação com diferentes atores, } \\
\text { grupos, coletivos e segmentos } \\
\text { sociais }\end{array}$ & $\begin{array}{l}\text { Melhorar a comunicação, participação e comprometimento de } \\
\text { diferente atores, grupos de interesse real e potencial da sociedade, } \\
\text { criando maior responsabilidade social, engajamento cívico e } \\
\text { solidariedade social, via atuação preferencial em redes }\end{array}$ \\
\hline $\begin{array}{l}\text { Articulação entre governos de um } \\
\text { mesmo nível }\end{array}$ & $\begin{array}{l}\text { Melhorar o entendimento e a busca de soluçães conjuntas entre } \\
\text { governo de mesmo nível, pela formação de parcerias, associações } \\
\text { em redes de atuação conjunta, de grupos de município ou grupos } \\
\text { de estado }\end{array}$ \\
\hline $\begin{array}{l}\text { Articulação entre governos de } \\
\text { diferentes níveis }\end{array}$ & $\begin{array}{l}\text { Melhorar o entendimento e a busca de soluções conjuntas entre } \\
\text { governo de diferentes níveis, pela formação de parcerias para } \\
\text { atuação conjunta, em que cada ente federativo cumpre } \\
\text { determinado papel, como parte de um sistema ou de uma rede, } \\
\text { visando alcançar objetivos comuns entre municípios e estados e a } \\
\text { União }\end{array}$ \\
\hline Transferibilidade & Criar condições e tecnologias transferíveis e aproveitáveis em \\
\hline
\end{tabular}




\begin{tabular}{|c|c|}
\hline & outras áreas, contextos, administrações e regiões \\
\hline $\begin{array}{l}\text { Ampliação do número de } \\
\text { beneficiários }\end{array}$ & $\begin{array}{l}\text { Gerar impactos não apenas para o público-alvo principal, mas } \\
\text { também sobre outros cidadãos e segmentos localizados ao redor, } \\
\text { passíveis de serem sensibilizados e beneficiados de forma indireta }\end{array}$ \\
\hline Permeabilidade ao público alvo & $\begin{array}{l}\text { Aproximar-se do público-alvo, ser entendível e compreensível, } \\
\text { suficientemente simples, informal e coerente com o modo de vida } \\
\text { prevalente, para ser facilmente contatado, assimilado e adotado na } \\
\text { vida cotidiana dos cidadãos }\end{array}$ \\
\hline $\begin{array}{l}\text { Simplificação da vida dos } \\
\text { cidadãos }\end{array}$ & $\begin{array}{l}\text { Facilitar e simplificar o acesso dos cidadãos a bens e serviços } \\
\text { públicos e sociais; deve racionalizar ações, visando maior eficácia, } \\
\text { sem desconsiderar aspectos de tradições, de afeições e de valores } \\
\text { do público-alvo }\end{array}$ \\
\hline Inclusão de minorias sociais & $\begin{array}{l}\text { Estimular a inclusão ou reinclusão de minorias desfavorecidas } \\
\text { historicamente na sociedade, privilegiando maior integração e } \\
\text { participação social de segmentos étnicos, de gênero, de idade e de } \\
\text { classes sociais que foram historicamente desfavorecidos e } \\
\text { prejudicados }\end{array}$ \\
\hline $\begin{array}{l}\text { Incorporação de tecnologias } \\
\text { facilitadoras da ação pública }\end{array}$ & $\begin{array}{l}\text { Estimular a introdução de novas tecnologias (como internet, } \\
\text { sistemas de acompanhamento informatizado e outros) que facilitem } \\
\text { e tornem mais eficaz a ação pública, rompendo ou quebrando } \\
\text { paradigmas de ação mais antigos e menos eficazes }\end{array}$ \\
\hline $\begin{array}{l}\text { Fortalecimento do poder de } \\
\text { gerenciamento para governos }\end{array}$ & $\begin{array}{l}\text { Fortalecer e até devolver capacidade de gerenciamento efetivo ao } \\
\text { setor público; ao mesmo tempo que delega ações, deve fortalecer a } \\
\text { capacidade de planejar, definir estratégias amplas e gerais, visando } \\
\text { articular melhor as ações de diferentes atores e setores da } \\
\text { sociedade }\end{array}$ \\
\hline Enfoque sistêmico & $\begin{array}{l}\text { Ter enfoque sistêmico, em que as partes desempenham um papel } \\
\text { integrativo para alcance de objetivos comuns; se aceita caminhos } \\
\text { ou opções alternativas (em vez de lineares e únicas); considerando- } \\
\text { se o sistema focado como contendo partes, e ao mesmo tempo, } \\
\text { fazendo parte de um sistema maior; se aceita constantes } \\
\text { prevenções, reavaliações e reajustes; se enfatiza mais perspectivas } \\
\text { dinâmicas e integrativas, do que estatísticas pontuais }\end{array}$ \\
\hline
\end{tabular}

Quadro 2 - Conjunto de características ou atributos presentes num projeto inovador Fonte: Adaptado de Klering e Andrade (2006, p. 92-95)

$\mathrm{Na}$ tentativa de compreender a inovação no setor público brasileiro a partir de práticas existentes, uma iniciativa importante foi a criação do Programa de Gestão Pública e Cidadania (GPC), em 1996. Spink (2006) explica que o objetivo do programa é focalizar o que está indo bem na esfera pública sub-nacional brasileira e de contribuir para aumentar o leque de conhecimentos disponíveis sobre experiências alternativas nas áreas de ação do Executivo, Legislativo, Judiciário e nas formas próprias de governo indígena.

Spink (2006) analisou uma base de dados contendo informações fornecidas por 100 programas, projetos e atividades semifinalistas do GPC e conclui que 


\begin{abstract}
...considerando o conjunto de respostas, não há como ignorar a clareza do recado dado na primeira e mais freqüente delas, responsável por $60 \%$ das afirmações, quando incluída as respostas múltiplas: assumindo a iniciativa na busca de novas soluções para problemas existentes. O papel do gestor público não é mais de administrar e controlar os serviços existentes, mas de resolver problemas e achar soluções efetivas. Uma resposta simples, mas ao mesmo tempo revolucionária dado o curto espaço de tempo da atual democracia brasileira. A segunda e a terceira respostas mais freqüentes - mudança no enfoque de como pensar a ação; inclusão ativa e coletiva, abrangendo participação e co-gestão na busca de soluções e no monitoramento de ações foram juntas responsáveis por mais de $40 \%$ das respostas. Talvez elas indiquem o caminho que começa a ser construído uma vez que se assume o papel dos gestores públicos é, fato, revolver os problemas sérios da sociedade dentro da qual foram eleitos. A sua presença marcante, mesmo em escala menor à resolução de problemas em si, é sem dúvida uma luz de otimismo na possibilidade de uma gestão pública aberta, com capacidade de pensar ampla e integradamente sobre co-gestão de serviços e o co-direcionamento das políticas públicas (SPINK, 2006, p.37).
\end{abstract}

Ao longo deste estudo foi demonstrada a influência da tecnologia da informação e comunicação (TIC) na inovação em serviços, e, o significado da inovação para o setor público. O setor público brasileiro é rico em serviços inovadores relacionados à $\mathrm{TIC}$, dentre os quais podemos relacionar ganhadores do $12^{\circ}$ e $13^{\circ}$ Concurso Inovação na Gestão Pública Federal, realizados em 2007 e 2008 respectivamente (MINISTÉRIO DO PLANEJAMENTO, ORÇAMENTO E GESTÃO, 2009):

- Simec

Sistema Integrado de Planejamento, Orçamento e Finanças do Ministério da Educação. Desenvolvido em software livre, utilizando modernas técnicas de mapeamento de processos, proporcionando melhoria significativa do planejamento e gestão das políticas e programas educacionais do Governo Federal. O Simec classificou-se em primeiro lugar no $13^{\circ}$ Concurso Inovação na Gestão Pública Federal;

- Sistema Nacional de Gestão de Atividades de Criminalística do Departamento de Polícia Federal

Foi concebido e desenvolvido com o intuito de racionalizar o acesso à informação, melhorar o desempenho do trabalho pericial e facilitar a administração centralizada da perícia no Departamento de Polícia Federal (DPF). Este sistema classificou-se em quinto lugar no $13^{\circ}$ Concurso Inovação na Gestão Pública Federal;

- Sisbio 
Sistema de Autorização e Informação em Biodiversidade. O Sisbio é um sistema informatizado de autorização e de informação que objetiva melhorar o atendimento a pesquisadores cujos estudos envolvem coleta de material biológico ou são desenvolvidos em unidades de conservação da natureza ou ainda, em cavernas. O Sisbio classificou-se em décimo lugar no $13^{\circ}$ Concurso Inovação na Gestão Pública Federal;

- Coleta de dados por computadores de mão para censos de proporções continentais

Foi concebido para tornar a coleta e a consolidação de dados mais ágeis e econômicas, aumentando a segurança. O Instituto Brasileiro de Geografia e Estatística está realizando a Contagem da População e o Censo Agropecuário 2007 com alternativa tecnológica para uso de computadores de mão - Personal Digital Assistant (PDA). É uma inovação mundial. Nenhum país de proporções continentais já realizou tal operação. Esta solução classificou-se em primeiro lugar no $12^{\circ}$ Concurso Inovação na Gestão Pública Federal;

- Portal da Transparência

Criado em novembro de 2004, tem por objetivo promover a transparência da gestão pública e estimular a participação e o controle social. O Portal viabiliza o acompanhamento efetivo da execução financeira de todos os programas e ações do Governo Federal, em linguagem simples, navegação amigável e sem necessidade de senhas, de modo que qualquer pessoa possa ter ampla noção sobre como é aplicado o dinheiro público. Estão disponíveis informações exatas, tempestivas e completas sobre recursos transferidos pelo Governo Federal aos outros entes públicos e diretamente ao cidadão; gastos diretos realizados pelo Governo Federal em compras ou contratação de obras e serviços; bem como, gastos realizados por meio de cartões de Pagamentos do Governo Federal. O Portal da Transparência é hoje o mais abrangente banco de dados sobre os gastos do Governo Federal aberto a toda sociedade, representando, assim, iniciativa inédita de transparência pública no Brasil e no mundo. Este sistema classificou-se em quinto lugar no $12^{\circ}$ Concurso Inovação na Gestão Pública Federal. 
No próximo item, será apresentada mais uma solução baseada em tecnologia da informação para o setor público brasileiro.

\subsection{INTEGRAÇÃO ENTRE A CONTA ÚNICA E O SPB}

Nos últimos 20 anos o Brasil passou por uma profunda reforma na área de finanças públicas, compreendendo reforma estruturais, institucionais, legais e organizacionais. Entre as mudanças ocorridas pode-se destacar a criação da Secretaria do Tesouro Nacional (STN), em 1986; a implantação do SIAFI, em 1987; e a criação da Conta Única do Tesouro Nacional, em 1988.

A implantação do SIAFI possibilitou a criação da Conta Única, quando permitiu que todas as unidades administrativas do Governo Federal acessem este sistema de informação de forma on-line. A idéia da Conta Única surgiu quando se definiu como diretriz do SIAFI que cada gestor teria um terminal ou teria acesso a um terminal, ligado diretamente a Brasília e dentro de um único sistema operacional e contábil. Portanto, como todos estariam interligados, os pagamentos entre eles não precisariam passar pela rede bancária (CASTRO; GARCIA, 2008).

Antes da criação da Conta Única, segundo Albuquerque, Medeiros e Feijó (2008), cada unidade administrativa do Governo Federal abria suas próprias contas bancárias e usualmente controlava determinados recursos mediante abertura de contas específicas. A efetiva implementação de adequado mecanismo de controle das disponibilidades financeiras de diversas unidades administrativas do Governo Federal somente foi possível com a implementação da Conta Única, no âmbito do SIAFI, o que propiciou as condições para eliminar as contas correntes mantidas na rede bancária. Deste modo, todos os recursos financeiros disponíveis de todas as entidades do governo central passaram a serem depositados na Conta Única.

A Conta Única é mantida no Banco Central do Brasil e operacionalizada pela STN. O Banco Central paga ao Tesouro Nacional remuneração sobre o saldo diário da Conta Única, segundo taxa compatível com as do mercado financeiro.

Para Castro e Garcia (2008), a Conta Única trouxe como conseqüência a lógica do novo Sistema de Pagamentos Brasileiro (SPB). O último grande avanço na Conta Única do Tesouro Nacional foi sua integração com o SPB, em 2002 (ALBUQUERQUE; MEDEIROS; FEIJÓ, 2008). 
$\mathrm{Na}$ visão de Albuquerque, Medeiros e Feijó (2008), um sistema de pagamentos é um conjunto de regras, procedimentos, instrumentos e sistemas operacionais que atuam de forma integrada com a finalidade de transferir recursos do pagador para o recebedor, com o objetivo de encerrar determinada obrigação existente entre as partes. As economias de mercado movimentam os recursos gerados pela atividade econômica, seja ela produtiva, comercial ou financeira, tanto em moeda local quanto em moeda estrangeira, por meio desses sistemas.

O SPB apresenta alto grau de automação, com crescente utilização de meios eletrônicos para transferência de fundos e liquidação de obrigações, em substituição aos instrumentos baseados em papel. Esses recursos possibilitam o processamento automático de operações desde a fase de contratação até a de liquidação final, que é utilizado em quase todos os segmentos do mercado financeiro.

Até meados dos anos 90, as mudanças no SPB foram motivadas pela necessidade de se lidar com altas taxas de inflação e, por isso, o progresso tecnológico então alcançado visou principalmente o aumento da velocidade de processamento das transações financeiras. Na reforma conduzida pelo Banco Central do Brasil em 2001 e 2002, o foco foi redirecionado para a administração de riscos. Nessa linha a entrada em funcionamento do Sistema de Transferência de Reservas (STR), em 22 de abril de 2002, marca o início de uma nova fase do SPB.

Com esta última mudança, o Banco Central do Brasil transformou o modo de operação do mercado financeiro do modelo Bach, de processamento noturno, para um modelo em tempo real, ou seja, a liquidação financeira das obrigações pôde passar a ser feita no próprio dia e não mais no dia seguinte (ALBUQUERQUE; MEDEIROS; FEIJÓ, 2008).

O novo modelo torna o mercado mais seguro, pois as operações somente são realizadas se os agentes dispuserem, na prática, de recursos em reservas ou títulos em custódia. Com certeza o risco sistêmico diminui, considerando-se que a distância entre a negociação e a liquidação agora é menor e este é um dos principais fatores que elevam o risco.

Afirmam Albuquerque, Medeiros e Feijó (2008) que a implantação do SPB a partir de 22 de abril de 2002, proporcionou ao Tesouro Nacional, como entidade integrante desse sistema, ganhos consideráveis no que se refere às rotinas de movimentação financeira da Conta Única.

As principais vantagens da integração da Conta Única com o SPB são: 
- As instituições financeiras que realizam operações com o Tesouro repassam, em tempo real, os recursos para a Conta Única, com contabilização automática na Unidade Gestora responsável;

- Recursos permanecem mais tempo à disposição do Tesouro Nacional, sendo remunerado durante esse período - em várias operações o prazo de ingresso de recursos na Conta Única foi reduzido e nas saídas de recurso da conta única o Tesouro Nacional passou, em algumas operações, a creditar o beneficiário diretamente por meio do SPB, eliminando a intermediação do agente financeiro, reduzindo o tempo de saída dos recursos da conta única e a data de crédito do beneficiário (ALBUQUERQUE; MEDEIROS; FEIJÓ, 2008);

- O Tesouro Nacional ficou mais próximo dos contribuintes, com a criação de mecanismo que possibilita o pagamento de tributos, recolhidos por meio de Documento de Arrecadação Federal (DARF), Guia da Previdência Social (GPS) e Guia de Recolhimento da União (GRU) que podem ser quitados diretamente no Tesouro (ALBUQUERQUE; MEDEIROS; FEIJÓ, 2008);

- Qualquer instituição financeira participante do SPB pode quitar seus débitos com o governo, diretamente no Tesouro Nacional, por meio das mensagens específicas, sem necessidade da intermediação dos bancos conveniados (ALBUQUERQUE; MEDEIROS; FEIJÓ, 2008);

- Os órgãos públicos da Administração Pública Federal, integrantes do SIAFI, passaram a utilizar-se do SPB quando emitem ordens bancárias para efetuar os seguintes pagamentos: transferências para instituições financeiras, salários, depósitos judiciais, precatórios e requisições de pequeno valor e recolhimento do fundo de garantia (ALBUQUERQUE; MEDEIROS; FEIJÓ, 2008).

Por parte do Tesouro Nacional, a integração com o SPB realizada em 2002 se deu, de forma parcial, com a criação de uma nova funcionalidade no SIAFI denominada SPB mainframe. As vantagens relatadas acima foram incorporadas pela mesma, porém a troca de mensagens diretamente com as instituições financeiras e requisitos exigidos pelo Banco Central como a existência de uma infra-estrutura redundante para a contingência do serviço, não puderam ser implementados. 
Seguindo esta trajetória, o SERPRO desenvolveu o Sistema de Operações do Tesouro Nacional (SOTN). Esta aplicação substitui o SPB mainframe do SIAFI. O SOTN é uma solução que permitirá à Secretaria do Tesouro Nacional - STN atuar como participante direto do Sistema de Transferência de Reservas (STR) e como prestador de serviços na Rede do Sistema Financeiro Nacional (RSFN), com a responsabilidade pelo monitoramento de seus lançamentos e recebimentos.

Os principais benefícios do SOTN em relação ao SPB mainframe são apresentados no Quadro 3.

\begin{tabular}{|c|c|}
\hline SPB mainframe & SOTN \\
\hline $\begin{array}{l}\text { Banco Central realiza ações de negócio, por } \\
\text { impossibilidade de a STN realizar }\end{array}$ & $\begin{array}{l}\text { A STN passa a realizar as funções de negócio, hoje } \\
\text { exercidas pelo Banco Central }\end{array}$ \\
\hline $\begin{array}{l}\text { Bancos podem solicitar estorno de } \\
\text { movimentações financeiras, que são pagas pelo } \\
\text { SIAFI com avaliação precária do mérito }\end{array}$ & $\begin{array}{l}\text { Há avaliação do mérito de solicitações de } \\
\text { movimentações financeiras }\end{array}$ \\
\hline $\begin{array}{l}\text { O SIAFI é o único instrumento para visibilidade } \\
\text { das operações realizadas }\end{array}$ & $\begin{array}{l}\text { Fornece controle e visualização das transações de } \\
\text { forma on-line }\end{array}$ \\
\hline \multirow[t]{2}{*}{ Não há contingência } & A infra-estrutura possui redundância e contingência \\
\hline & $\begin{array}{l}\text { A solução permite contingência do SIAFI, por meio } \\
\text { da digitação autônoma de mensagens. Assim, numa } \\
\text { eventual falha do SIAFI, podem ser digitadas de } \\
\text { modo manual, mensagens emergenciais. }\end{array}$ \\
\hline
\end{tabular}

Quadro 3 - Benefícios do SOTN em relação ao SPB mainframe

Estes benefícios permitiram à STN atuar, de forma autônoma, como participante e provedor de serviços do SPB, assumindo funções que hoje o Banco Central do Brasil realiza para o Tesouro Nacional. 


\section{METODOLOGIA}

Neste capítulo são apresentados o método e as técnicas de pesquisa adotados neste estudo, considerando o objetivo geral de identificar se a solução de TIC responsável pela integração da Conta Única com o SPB pode ser considerada um serviço inovador.

\subsection{TIPO DE PESQUISA}

Esta pesquisa se caracteriza como um estudo de caso, qualitativo e de natureza descritiva, o qual tem como objeto o SOTN. Neste estudo de caso foram realizadas entrevistas e pesquisa documental. O objetivo deste estudo é identificar se a solução de TIC responsável pela integração da Conta Única com o SPB pode ser considerada um serviço inovador.

Yin (2005) define duas características tecnicamente importantes de um estudo de caso. A primeira enfoca o escopo de um estudo de caso: "Um estudo de caso é uma investigação empírica que investiga um fenômeno contemporâneo dentro de seu contexto da vida real, especialmente quando os limites entre o fenômeno e o contexto não estão claramente definidos" (YIN, 2005, p. 32). A segunda, a definição técnica

\footnotetext{
A investigação de um estudo de caso enfrenta uma situação tecnicamente única em que haverá muito mais variáveis de interesse do que pontos de dados, e, como resultado, baseia-se em várias fontes de evidências, com os dados precisando convergir em um formato triângulo, e, como outro resultado, beneficia-se do desenvolvimento prévio de proposições teóricas para conduzir a coleta e a análise de dados (YIN, 2005, p. 33).
}

Os estudos denominados qualitativos têm como preocupação fundamental o estudo e a análise do mundo empírico em seu ambiente natural. Nessa abordagem valoriza-se o contato direto e prolongado do pesquisador com o ambiente e a situação que está sendo pesquisada. Na pesquisa qualitativa o pesquisador deve aprender a usar sua própria pessoa como o instrumento mais confiável de observação, seleção, análise e interpretação dos dados coletados (GODOY, 1995).

Entende-se que este estudo de caso é descritivo porque tem como propósito essencial descrever o caso em estudo, sem o objetivo de identificar relações causais. 


\subsection{CARACTERIZAÇÃO DA ORGANIZAÇÃO}

O SERPRO é uma empresa pública vinculada ao Ministério da Fazenda. Foi criada no dia $1^{\circ}$ de dezembro de 1964, com o objetivo de modernizar e dar agilidade a setores estratégicos da Administração Pública brasileira. A Empresa, cujo negócio é a prestação de serviços em Tecnologia da Informação e Comunicações para o setor público, é considerada uma das maiores Organizações do setor, na América Latina (SERPRO, 2009a).

Desde a criação da STN, ocorrida em 1986, o SERPRO vem prestando serviços àquela instituição, através da Superintendência de Relacionamento com Clientes - Administração Financeira (SUNAF). A SUNAF é uma unidade de gestão do SERPRO que presta serviços no segmento de administração financeira do setor público, cujo principal cliente é a Secretaria do Tesouro Nacional (STN). A SUNAF está diretamente vinculada à Diretoria de Desenvolvimento e Negócios, representada na Figura 2. Dentre os serviços prestados estão a construção dos sistemas SIAFI e SOTN.

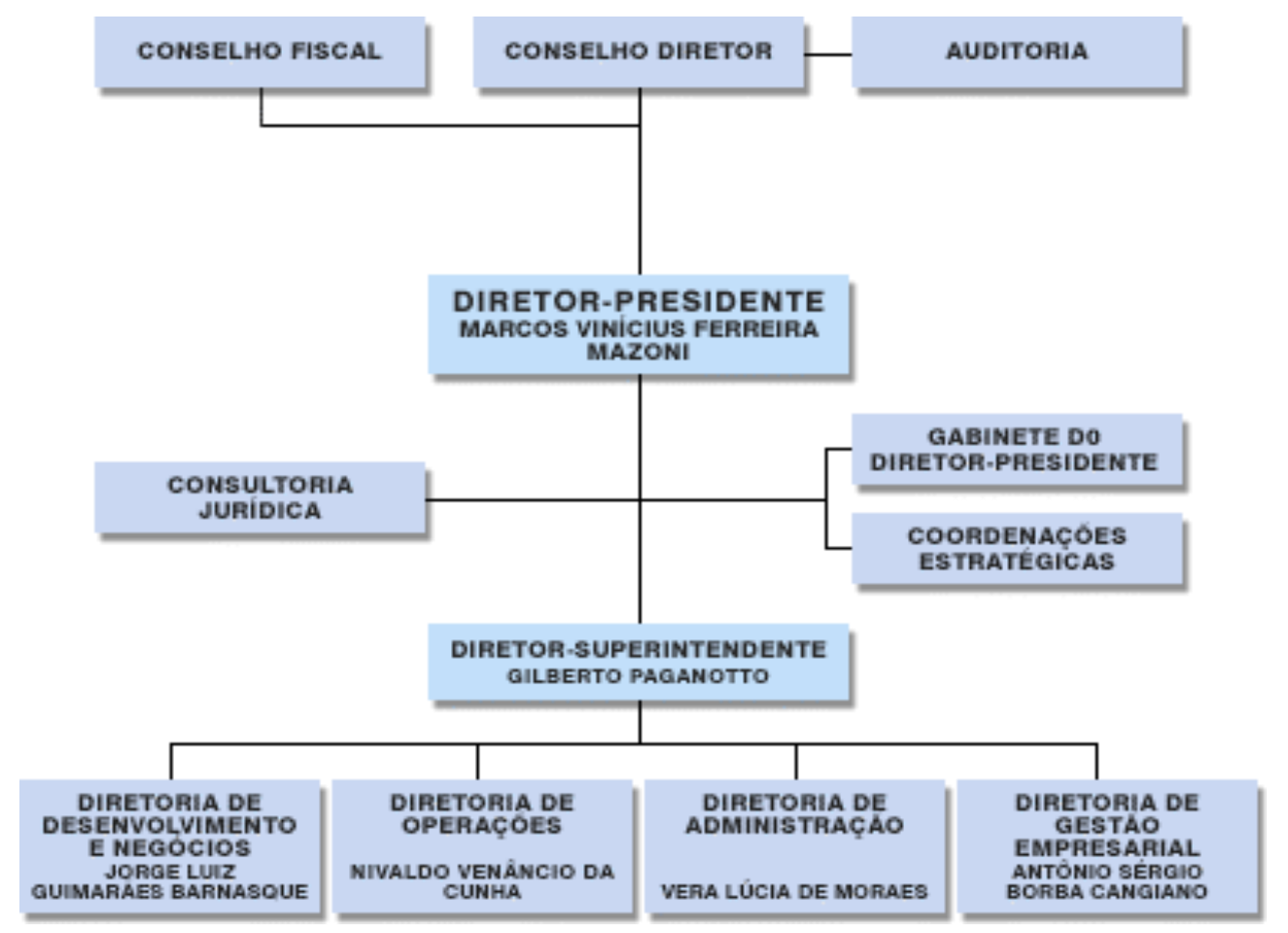

Figura 2 - Organograma SERPRO

Fonte: SERPRO, disponível em: http://www.serpro.gov.br (Acesso em: 15 fev.2009) 


\subsection{PARTICIPANTES DA PESQUISA E AMOSTRA DE DOCUMENTOS}

As evidências para um estudo de caso podem vir de seis fontes distintas: documentos, registros em arquivo, entrevistas, observação direta, observação participante e artefatos físicos (YIN, 2005).

Neste estudo foram utilizadas as seguintes evidências:

- Documentos

Relatórios de posicionamento do projeto SOTN e publicações na revista Tema - revista do SERPRO;

- Registros em Arquivo

Site corporativo residente na intranet da organização (foram pesquisados: Planejamento Estratégico Empresarial, Plano Diretor de Tecnologia da Informação (PDTI), Balanço Social, Relatório de Gestão do SERPRO, Programa SERPRO de Gerenciamento de Projetos (PSGP), Programa SERPRO de Gerenciamento de Serviços (PSGTI), Programa SERPRO de Segurança (PSS), Processo SERPRO de Desenvolvimento de Soluções (PSDS)); Especificações Técnicas para as Instituições Financeiras - Ambiente de Pagamentos, Sistema de Controle, Acompanhamento e Avaliação de Resultados dos Projetos; repositório que contempla toda a documentação do SOTN (foram pesquisados: Requisitos Não-Funcionais do Piloto SOTN (SSP01), Plano de Projeto do SOTN, Projeto Básico para a produção do SOTN, Documento de Solução da Arquitetura - DAS do Piloto SOTN (SSP04), Ambientes de Produção da Solução Piloto SOTN (SSP05), Testes de Tecnologia da Solução Piloto SOTN (SSP12)); e Estratégia Geral de Tecnologia da Informação (EGTI) de 2008; e

- Entrevistas

Entrevistas individuais semi-estruturadas.

Participaram desta pesquisa oito empregados da SUNAF envolvidos com o SOTN. Foram selecionados sete participantes do projeto SOTN, sendo um deles o gerente do projeto. Também participou o gerente responsável pela SUNAF.

Os entrevistados foram selecionados em função tanto do conhecimento a respeito do projeto SOTN quanto da solução que o mesmo implementa e podem ser classificados em três grupos: 
- Primeiro grupo

Aqueles que fazem parte da alta liderança da SUNAF e, portanto, têm uma visão estratégica do projeto SOTN. São o gerente responsável pela SUNAF e o gerente do projeto;

- Segundo grupo

Aqueles que estão envolvidos com o projeto SOTN desde o seu início, e que fazem parte da equipe que o compõe e, portanto, têm um profundo conhecimento sobre o projeto SOTN. São três participantes do projeto SOTN. Os três são analistas de informática e pertencem a equipe de gerenciamento do projeto. Dois deles fazem a interação com o cliente e com diversas áreas do SERPRO - como: centro de dados, rede, gerenciamento de serviços e desenvolvimento de software - com o objetivo de implantar o sistema Piloto do SOTN. O Piloto do SOTN é uma solução de mensageria, ou seja, permite a troca de mensagens com as entidades participantes da RSFN e com os sistemas participantes do SOTN, sendo a principal solução integrante do SOTN. Um dos entrevistados faz interação com o cliente e com diversas áreas do SERPRO, como as citadas anteriormente, com o objetivo de implantar a solução de gerenciamento de serviços;

- Terceiro grupo

Aqueles que estão envolvidos com o projeto SOTN a menos de um ano, e que fazem parte da equipe que o compõe e, portanto, não têm um profundo conhecimento sobre o projeto SOTN. São três participantes do projeto SOTN. Os três são analistas de informática que pertenciam à equipe de garantia de uso da SUNAF, e passaram a integrar a equipe de gerenciamento de projeto em dezembro de 2008. Um deles faz interação com o cliente e com diversas áreas do SERPRO, como as citadas no segundo grupo, com o objetivo de solucionar problemas da infra-estrutura e dois deles atuam principalmente na estruturação da entrega do serviço e garantia de uso da solução SOTN.

\subsection{INSTRUMENTO DA COLETA DE DADOS}

As informações que permitiram atingir o objetivo geral de "Identificar se a solução de TIC responsável pela integração da Conta Única com o SPB pode ser 
considerada um serviço inovador" foram coletadas por meio de entrevistas e de documentos obtidos na empresa pesquisada.

As entrevistas foram realizadas de modo individual, a partir de um conjunto de questões semi-estruturadas, elencadas no roteiro descrito no Apêndice $A$, que orientou a pesquisadora na condução da entrevista. Este roteiro foi estruturado em cinco blocos:

- Identificação do Entrevistado - aspectos profissionais relevantes que permitem identificar a contribuição do entrevistado com o objetivo geral da pesquisa;

- Origem do Projeto SOTN - caracterização do projeto SOTN. Este bloco de questões é também utilizado para desinibir o entrevistado antes do início das perguntas que realmente contribuem para atingir o objetivo geral da pesquisa;

- Implementação do Projeto SOTN - permite avaliar o potencial de inovação do projeto SOTN;

- Solução Tecnológica Adotada no SOTN - permite avaliar o potencial de inovação tecnológica do projeto SOTN;

- Inovação Tecnológica no Serviço SOTN - permite avaliar a inovação tecnológica no SOTN. Neste último bloco, as três primeiras questões tiveram o objetivo de explicar as três fases que compõe o ciclo reverso do produto, permitindo, deste modo, avaliar a inovação tecnológica em serviço para o SOTN.

Os entrevistados pertencentes ao terceiro grupo, conforme classificação apresentado no item 3.3, responderam apenas o primeiro e o último bloco.

Os documentos pesquisados foram utilizados para confrontar as respostas de cada uma das perguntas dos três últimos blocos do roteiro de entrevista.

O cumprimento dos objetivos específicos deste estudo foi buscado a partir dos instrumentos de coleta relatados no Quadro 4. 


\begin{tabular}{|l|l|}
\hline Objetivos específicos & Instrumentos de coleta \\
\hline Discutir conceitos de inovação em serviços & Pesquisa bibliográfica \\
\hline Discutir conceitos de inovação no setor público & Pesquisa bibliográfica \\
\hline Analisar a integração entre a Conta Única e o SPB & Pesquisa bibliográfica \\
\hline $\begin{array}{l}\text { Definir um modelo de análise para identificar se a solução de TIC } \\
\text { responsável pela integração da Conta Única com o SPB pode ser } \\
\text { considerada um serviço inovador }\end{array}$ & Pesquisa bibliográfica \\
\hline $\begin{array}{l}\text { Identificar a inovação em solução de TIC a partir da solução de } \\
\text { integração da Conta Única com o SPB }\end{array}$ & Entrevistas e pesquisa documental \\
\hline
\end{tabular}

Quadro 4 - Instrumento de coleta para os objetivos específicos

Conforme o Quadro 4, foram três os instrumentos de coleta utilizados: pesquisa bibliográfica, entrevistas e pesquisa documental.

\subsection{PROCEDIMENTOS DA COLETA DE DADOS}

Tanto as entrevistas quanto a pesquisa documental foram realizadas e registradas pessoalmente pela pesquisadora.

No caso das entrevistas, foi esclarecido previamente junto aos entrevistados que a pesquisa objetivava coletar dados para uma pesquisa acadêmica. Foi garantido sigilo sobre o conteúdo das informações coletadas e o anonimato dos entrevistados. A forma de registro dos dados obtidos nas entrevistas foi a gravação direta com a autorização dos entrevistados.

No caso da pesquisa documental, as evidências foram coletadas a partir de duas fontes de informação da Empresa pesquisada: documentos e registros em arquivos, conforme item 3.3 deste estudo.

\subsection{ANÁLISE DOS DADOS}

A análise de dados envolveu o exame dos dados obtidos por meio das entrevistas e dos dados obtidos através da pesquisa nos documentos internos da organização pesquisada.

Gaskell (2002) define que "o objetivo amplo da análise é procurar sentido e compreensão. O que é realmente falado constitui os dados, mas a análise deve ir além da aceitação deste valor aparente".

Para a análise das informações obtidas foram utilizados dois métodos que permitiram analisar a inovação em serviços e que foram discutidos no referencial teórico. 
O primeiro método apresentado foi o modelo do ciclo reverso do produto proposto por Barras (1986) que, segundo Vargas e Zawislak (2005), mostrou-se adequado para análise de difusão tecnológica nas empresas de serviços.

O segundo método apresentado foi baseado em um conjunto de características/atributos de práticas inovadoras que facilitam a identificação e o reconhecimento do potencial de inovação de um projeto que tenha a intenção de transformar para melhor realidades e sociedades, com base em gestões públicas eficazes (KLERING; ANDRADE, 2005).

Apesar de no referencial teórico ter-se discutido primeiro o modelo do ciclo reverso do produto e depois o conjunto de características/atributos de práticas inovadoras. Optou-se por mostrá-los a partir do próximo item 3.6.1 de modo inverso, pois, no caso estudado, o projeto SOTN foi criado para implementar o serviço SOTN. Portanto, cronologicamente, primeiro tem-se o projeto e depois o serviço.

\subsubsection{POTENCIAL DE INOVAÇÃO DO PROJETO SOTN}

O projeto SOTN foi criado com o objetivo de implantar uma solução para a STN que implementa a integração entre a Conta Única e o SPB.

Para avaliar se o projeto SOTN é inovador, foram selecionadas cinco características/atributos entre as vinte características/atributos apresentadas no Quadro 2.

As quinze características/atributos que não foram selecionadas, bem como o motivo de as mesmas não terem sido selecionadas, estão demonstrados no Quadro 5. 


\begin{tabular}{|c|c|}
\hline Características/Atributos & $\begin{array}{l}\text { Motivo de não serem } \\
\text { selecionadas }\end{array}$ \\
\hline $\begin{array}{l}\text { Melhoria da qualidade de vida do público-alvo; Auto-sustentabilidade; } \\
\text { Credibilidade pública; Permeabilidade ao público alvo; e } \\
\text { Fortalecimento do poder de gerenciamento para governos }\end{array}$ & $\begin{array}{l}\text { Não se aplicam a projetos } \\
\text { voltados à implantação de } \\
\text { sistemas de informação }\end{array}$ \\
\hline $\begin{array}{l}\text { Desenvolvimento de tecnologia e responsabilidade na utilização de } \\
\text { recursos e oportunidades; Consolidação e ampliação do diálogo com } \\
\text { a sociedade civil; Articulação com diferentes setores sociais; } \\
\text { Articulação com diferentes atores, grupos, coletivos e segmentos } \\
\text { sociais; Articulação entre governos de um mesmo nível; e Articulação } \\
\text { entre governos de diferentes níveis }\end{array}$ & $\begin{array}{l}\text { Não são adequadas para } \\
\text { avaliar o potencial de inovação } \\
\text { do projeto SOTN, pois não } \\
\text { fazem parte das atribuições da } \\
\text { STN }\end{array}$ \\
\hline Viabilidade técnica, gerencial, econômica e financeira & $\begin{array}{l}\text { É uma rotina que deve estar } \\
\text { presente em qualquer projeto } \\
\text { que prima por práticas de } \\
\text { gestão e, portanto, não pode } \\
\text { ser considerada inovadora }\end{array}$ \\
\hline $\begin{array}{l}\text { Simplificação da vida dos cidadãos; Inclusão de minorias sociais; e } \\
\text { Enfoque sistêmico }\end{array}$ & $\begin{array}{l}\text { Não se aplicam às } \\
\text { especificações do projeto SOTN }\end{array}$ \\
\hline
\end{tabular}

Quadro 5 - Características/atributos não selecionados

Fonte: Adaptado de klering e Andrade (2006, p. 92-95)

O Quadro 6 retrata as características/atributos selecionados. Estas cinco características/atributos atendem ao propósito de medir o potencial de inovação no projeto SOTN.

\begin{tabular}{|c|c|}
\hline Características/Atributos & Descrição \\
\hline $\begin{array}{l}\text { Introdução de mudanças, qualitativas } \\
\text { e quantitativas, em relação a práticas } \\
\text { anteriores }\end{array}$ & $\begin{array}{l}\text { Introduzir novos modos ou modelos de provisão de bens e } \\
\text { serviços, ser capaz de mudar hábitos ou costumes de trabalho, } \\
\text { desenvolver produtos e serviços, tanto novos, quanto renovar } \\
\text { antigos }\end{array}$ \\
\hline Accountability & $\begin{array}{l}\text { Ter suas contas e seu funcionamento apresentados de forma } \\
\text { clara, objetiva e transparente aos seus apoiadores e à sociedade } \\
\text { em geral, com prestações regulares de contas }\end{array}$ \\
\hline Transferibilidade & $\begin{array}{l}\text { Criar condições e tecnologias transferíveis e aproveitáveis em } \\
\text { outras áreas, contextos, administrações e regiões }\end{array}$ \\
\hline $\begin{array}{l}\text { Ampliação do número de } \\
\text { beneficiários }\end{array}$ & $\begin{array}{l}\text { Gerar impactos não apenas para o público-alvo principal, mas } \\
\text { também sobre outros cidadãos e segmentos localizados ao } \\
\text { redor, passíveis de serem sensibilizados e beneficiados de forma } \\
\text { indireta }\end{array}$ \\
\hline $\begin{array}{l}\text { Incorporação de tecnologias } \\
\text { facilitadoras da ação pública }\end{array}$ & $\begin{array}{l}\text { Estimular a introdução de novas tecnologias (como internet, } \\
\text { sistemas de acompanhamento informatizado e outros) que } \\
\text { facilitem e tornem mais eficaz a ação pública, rompendo ou } \\
\text { quebrando paradigmas de ação mais antigos e menos eficazes }\end{array}$ \\
\hline
\end{tabular}

Quadro 6 - Conjunto de características/atributos que permitem identificar se o projeto SOTN é inovador Fonte: Adaptado de klering e Andrade (2006, p. 92-95) 
A partir das respostas obtidas nas entrevistas e com a pesquisa documental, foram avaliadas cada uma das características/atributos, a fim de se determinar o potencial de inovação do projeto SOTN. Já no que diz respeito à inovação tecnológica do SOTN, a análise tem por base, além dos documentos coletados, as respostas concedidas às questões apresentadas nos bloco 3 e 4 do Roteiro de Entrevistas, conforme Apêndice A.

\subsubsection{INOVAÇÃO TECNOLÓGICA EM SERVIÇOS PARA O SOTN}

Para avaliar a inovação tecnológica em serviços para o SOTN, sistema que integra a Conta Única e o SPB, foi analisado em que fase do modelo do ciclo reverso do produto o SOTN está situado, a partir das respostas obtidas nas entrevistas.

As perguntas que permitiram avaliar a inovação tecnológica do SOTN, são as apresentadas no Bloco 5 do Roteiro de Entrevistas, conforme Apêndice A.

No Roteiro de Entrevistas, as fases do ciclo reverso do produto foram nomeadas, conforme Quadro 1, ou seja:

- Primeira fase foi nomeada como melhoria da eficiência;

- Segunda fase foi nomeada como melhoria da qualidade;

- Terceira fase foi nomeada como novos serviços. 


\section{APRESENTAÇÃO E ANÁLISE DOS RESULTADOS}

Neste capítulo são apresentados e analisados os resultados das duas categorizações - potencial de inovação do projeto SOTN e inovação tecnológica em serviços para o SOTN - que permitiram identificar se a solução de TIC responsável pela integração da Conta Única com o SPB pode ser considerada um serviço inovador.

\subsection{POTENCIAL DE INOVAÇÃO DO PROJETO SOTN}

Nesta seção são apresentados e analisados os resultados da categorização que permite avaliar o potencial de inovação do projeto SOTN segundo um conjunto de características/atributos de práticas inovadoras identificadas por Klering e Andrade (2006), apresentadas no Quadro 6.

\subsubsection{INTRODUÇÃO DE MUDANÇAS, QUALITATIVAS E QUANTITATIVAS, EM RELAÇÃO A PRÁTICAS ANTERIORES}

Neste ponto, a análise se debruça sobre os efeitos da introdução de novos modos ou modelos de provisão de bens e serviços ao avaliar sua capacidade de mudar hábitos e costumes de trabalho, desenvolver produtos e serviços, tanto novos quanto renovar antigos. No caso analisado, a introdução de mudanças em relação a práticas anteriores pode ser confirmada principalmente por processos, tecnologias e soluções geradas ou melhoradas pelo projeto SOTN.

Os principais processos corporativos que foram adequados em função do projeto SOTN são provenientes dos programas:

- Programa SERPRO de Gerenciamento de Projetos (PSGP)

É responsável pela implementação do conjunto de processos que compõem o macroprocesso de gerenciamento de projetos do SERPRO que foi desenvolvido tendo como base as melhores práticas recomendadas pelo Guia PMBOK® - Conjunto de Conhecimentos em Gerenciamento de Projetos (SERPRO, 2009b);

- Programa SERPRO de Gerenciamento de Serviços (PSGTI)

É responsável pela definição e implantação de um modelo para efetivar a gestão, identificação e inter-relacionamento das várias atividades envolvidas no aperfeiçoamento da estrutura para entregar, mensurar e aperfeiçoar o gerenciamento de serviços em Tecnologia da Informação e 
Comunicação (TIC) que foi desenvolvido tendo como base o modelo de referência Information Technology Infrastructure Library (ITIL). O ITIL aglutina os melhores processos e práticas para ancorar a gestão de serviços de TIC (SERPRO, 2009d);

- Programa de Segurança do SERPRO (PSS)

Segue normas e padronizações especificadas por diversos órgãos e instituições nacionais e internacionais, com foco na manutenção da chamada "pirâmide básica da segurança" - confidencialidade, integridade e disponibilidade (SERPRO, 2009e).

Foi criado um novo processo que até o momento não foi incluído em um programa corporativo. Este processo está sendo tratado como uma necessidade do projeto e não foi apresentando para a área responsável pelos programas corporativos da empresa. Está descrito no documento Testes de Tecnologia da Solução Piloto SOTN (SSP12) que documenta o conjunto de testes de validação de tecnologia e arquitetura da solução SOTN, incluindo o planejamento, o resultado da execução dos testes e um parecer conclusivo sobre as tecnologias utilizadas para construção e produção/manutenção do sistema Piloto do SOTN (SERPRO, 2008).

Para reforçar a adequação dos processos corporativos em função do projeto SOTN, tem-se o seguinte relato de um dos entrevistados que conforme item 3.3 deste estudo está classificado no primeiro grupo de entrevistados:

\begin{abstract}
O SOTN é um serviço de missão crítica e envolve as finanças públicas, tem um nível de serviço muito rigoroso que se reflete na arquitetura do sistema e que possibilitou a especialização e maturidade no uso dos processos e de melhor e novas tecnologias em diversos segmentos do SERPRO como: desenvolvimento, rede, centro de dados e gestão de serviços. Este serviço exigiu que as unidades que trabalhavam de forma independente, passassem a trabalhar de forma integrada, com esta integração o SERPRO ganha: visão de serviço; maturidade na gestão de serviços; maturidade nos testes, que focaram o serviço e não apenas a aplicação, pela exigência de documentação e comprovação dos mesmos; e refinamento dos processos corporativos que podem ser exemplificados pelo gerenciamento de riscos.
\end{abstract}

Este entrevistado informa, ainda, que

O projeto SOTN acrescentou templates novos no processo de gerenciamento de projetos do SERPRO, principalmente para relatórios estratégico, tático e operacional. 
Outro entrevistado, classificado no segundo grupo de entrevistados, complementou

\begin{abstract}
O projeto SOTN nasceu como um projeto estratégico e, como tal, utilizou todo o ferramental para gerenciar projetos que foi definido ao longo do próprio desenvolvimento do projeto. À medida que as ferramentas foram desenvolvidas o projeto foi usado como cobaia.
\end{abstract}

A principal tecnologia que atende a esta característica/atributo é o software livre. O Plano Diretor de Tecnologia da Informação (PDTI) do SERPRO, documento que serve de guia para os próximos dois anos para apoiar a organização nas decisões estratégicas relativas à Tecnologia da Informação (SERPRO, 2009f) está alinhado à Estratégia Geral de Tecnologia da Informação (EGTI) de 2008 para a Administração Pública Federal, que foi desenvolvida com o objetivo de estabelecer bases para a transição entre a situação atual de gestão dos ambientes de informática do Executivo Federal - heterogênea e em geral vulnerável (MINISTÉRIO DO PLANEJAMENTO, ORÇAMENTO E GESTÃO, 2008). O uso do software livre, além de um princípio do EGTI, é um dos Direcionamentos Estratégicos do SERPRO, conforme o segundo item do Quadro 7 que correlaciona os princípios do EGTI com os Direcionamentos Estratégicos do SERPRO "Utilização de Software Livre como recurso estratégico para implementação do Governo Eletrônico (e-Gov)".

Em relação ao uso de software livre, para o entrevistado classificado no primeiro grupo de entrevistados "um dos aspectos mais relevantes da solução SOTN foi o uso do software livre na aplicação e em sistema operacional de servidores". 


\begin{tabular}{|c|c|}
\hline Princípio EGTI & Direcionamentos estratégicos do SERPRO \\
\hline $\begin{array}{l}\text { Promoção da cidadania e } \\
\text { inclusão digital }\end{array}$ & $\begin{array}{l}\text {.Tornar o SERPRO um referencial nas esferas públicas de práticas de } \\
\text { Cidadania e de Responsabilidade Sócio-ambiental }\end{array}$ \\
\hline \multirow{3}{*}{$\begin{array}{lr}\text { Utilização de } & \text { Software } \\
\text { Livre como } & \text { recurso } \\
\text { estratégico } & \text { para } \\
\text { implementação do } & \\
\text { e-Gov } & \end{array}$} & $\begin{array}{l}\text { - Buscar a sensibilização e o convencimento dos órgãos públicos quanto à } \\
\text { importância do uso de software livre }\end{array}$ \\
\hline & $\begin{array}{l}\text { - Atuar de forma a evitar o aprisionamento tecnológico nos segmentos de } \\
\text { software, hardware, e pessoas, intensificando e estruturando a prática de } \\
\text { comunidades virtuais }\end{array}$ \\
\hline & $\begin{array}{l}\text {. Tornar o SERPRO um referencial de excelência no uso de Software Livre e } \\
\text { padrões abertos que possibilitem a integração, a interoperabilidade, o } \\
\text { compartilhamento e a cooperação no desenvolvimento das soluções de TI }\end{array}$ \\
\hline \multirow[t]{5}{*}{$\begin{array}{l}\text { Racionalização dos } \\
\text { recursos de } \mathrm{TI}\end{array}$} & $\begin{array}{l}\text { - Utilizar a infra-estrutura de modo compartilhado, buscando a redução de } \\
\text { custos, a virtualização e a racionalização no uso }\end{array}$ \\
\hline & $\begin{array}{l}\text {. Praticar o reuso e o compartilhamento de componentes de Software, com } \\
\text { ênfase na padronização de dados e integração de processos e de serviços }\end{array}$ \\
\hline & $\begin{array}{l}\text { Manter permanentemente atualizada a capacidade da infra-estrutura } \\
\text { tecnológica instalada }\end{array}$ \\
\hline & $\begin{array}{l}\text { - Manter permanentemente atualizadas as tecnologias empregadas na } \\
\text { segurança da informação, com ênfase nos processos de contingência }\end{array}$ \\
\hline & $\begin{array}{l}\text { Consolidar a imagem da Empresa como fornecedora de soluções } \\
\text { integradoras e estruturadoras dos macroprocessos do Governo Federal }\end{array}$ \\
\hline \multirow[t]{4}{*}{ Gestão do Conhecimento } & $\begin{array}{l}\text { - Utilizar amplamente práticas necessárias à facilitação da criação e } \\
\text { compartilhamento do conhecimento, envolvendo todas as pessoas da } \\
\text { organização }\end{array}$ \\
\hline & $\begin{array}{l}\text { - Manter o corpo funcional e gerencial permanentemente capacitados para o } \\
\text { pleno exercício das suas respectivas atividades }\end{array}$ \\
\hline & $\begin{array}{l}\text { - Intensificar a cooperação tecnológica com o meio acadêmico, envolvendo } \\
\text { as pessoas de acordo com a dimensão da capilaridade da Empresa }\end{array}$ \\
\hline & $\begin{array}{l}\text { Ser uma Empresa reconhecida como fornecedora de serviços de tecnologia } \\
\text { cuja principal base seja o conhecimento da Administração Pública e a } \\
\text { inteligência }\end{array}$ \\
\hline \multirow[t]{6}{*}{$\begin{array}{l}\text { Integração do Governo } \\
\text { Eletrônico - e-Gov }\end{array}$} & $\begin{array}{l}\text { - Atuar de forma compartilhada e cooperativa nas soluções de } \mathrm{TI} \text {, com foco } \\
\text { nas demandas do governo federal para a democratização da informação em } \\
\text { benefício da sociedade }\end{array}$ \\
\hline & . Alinhar o planejado com sua efetiva contratação \\
\hline & $\begin{array}{l}\text { - Adotar padrões de desenvolvimento de software (incluindo os padrões } \\
\text { definidos no e-MAG e e-PING) }\end{array}$ \\
\hline & $\begin{array}{l}\text { - Adotar padrões na contratação de bens e serviços, e de serviços de infra- } \\
\text { estrutura }\end{array}$ \\
\hline & $\begin{array}{l}\text { Melhorar os processos de planejamento da capacidade presente e futura de } \\
\text { recursos técnicos e humanos }\end{array}$ \\
\hline & . Executar Plano de Capacitação de Tecnologia da Informação \\
\hline
\end{tabular}

Quadro 7 - Princípios da EGTI com os Direcionamentos Estratégicos do SERPRO Fonte: PDTI do SERPRO

A principal solução de provimento de serviços foi a de gerenciamento de serviços criada para o SOTN. Esta solução está descrita no Ambientes de Produção da Solução Piloto SOTN (SSP05) que apresenta a infra-estrutura adotada pelo SERPRO para prover o serviço de operação continuada do SOTN (SERPRO, 2009h). Três 
subprojetos do projeto SOTN foram responsáveis pela implantação da solução de gerenciamento de serviços:

- Solução de Monitoração de Serviços do SOTN

Visa adotar um processo para o gerenciamento do serviço SOTN, focado na busca pela entrega do serviço;

- Painel de Informações do SOTN

Visa prover à STN uma forma eficiente de visualizar e acompanhar a prestação de serviços contratados junto ao SERPRO. Dessa forma, além de o cliente poder visualizar as ocorrências on-line, também poderá gerar relatórios de disponibilidade, taxas de processamento e quantidade de mensagens transmitidas pelas instituições financeiras;

- Central de Monitoração de Serviços

Visa prover à STN uma gestão eficiente e pró-ativa ante os serviços contratos junto ao SERPRO, na busca de reduzir a indisponibilidade dos mesmos. Para tanto, deverá ser realizada a monitoração por meio de ferramentas de gerenciamento, que tem como objetivo dar uma visão ágil dos incidentes na árvore de serviços e sua propagação, para assim prover um rápido re-estabelecimento dos serviços.

Estes subprojetos, além de serem responsáveis pela execução da solução de gerenciamento de serviços, provocaram adequações no PSGTI (SERPRO, 2009d).

Em relação à solução de gerenciamento de serviços, o responsável pela interação com o cliente e com diversas áreas do SERPRO com o objetivo de implantar a solução de gerenciamento de serviços, disse que "a própria exigência dos níveis de serviço possibilitou um novo modelo de gestão do serviço, modelo este que será utilizado na Empresa". Outro entrevistado, classificado no primeiro grupo de entrevistados, afirmou:

\footnotetext{
Este é um novo negócio para o Cliente e para o SERPRO, que teve que aprender e, portanto, construir um novo modelo de gerenciamento de serviço, pois este serviço exige solução em tempo real, já que há uma grade horária diária, onde as operações têm que ser realizadas dentro da mesma.
}

Este último entrevistado acrescentou, ainda, que "foram feitas várias visitas a instituições financeiras para conhecer como suas áreas de TI se estruturaram para monitorar o serviço SPB". 
Pode-se considerar, portanto, com base na pesquisa documental e nas entrevistas, que o projeto SOTN provocou mudanças, tanto quantitativas como qualitativas em relação às práticas anteriores da organização.

\subsubsection{ACCOUNTABILITY}

O SOTN foi criado como projeto estratégico em 2005 e, no planejamento estratégico do SERPRO dos anos seguintes, foi confirmado como tal. Segundo um dos entrevistados classificado no segundo grupo de entrevistados, "como um projeto estratégico, utilizou todo o ferramental exigido pelo processo de gerenciamento de projetos do SERPRO e que foi definido ao longo do próprio desenvolvimento do projeto SOTN".

O PDTI (SERPRO, 2009f), o PSGP (SERPRO, 2009b) e o Processo SERPRO de Desenvolvimento de Soluções (PSDS) criado com o objetivo de padronizar e documentar as atividades realizadas para conceber soluções de TI para os clientes do SERPRO (SERPRO, 2009c) normatizam a forma de trabalhar por projeto e o desenvolvimento de soluções. O entrevistado pertencente ao primeiro grupo de entrevistados, afirma que

\footnotetext{
Existiu a prestação de contas em todos os níveis, inclusive o financeiro. Os próprios processos de gerenciamento de projeto e desenvolvimento de soluções do SERPRO propiciam a prestação de contas. Cada etapa do projeto foi comunicada, formalizada e homologada pelo cliente.
}

Segundo o outro entrevistado também classificado no primeiro grupo de entrevistados "foi criada uma estrutura para fazer a gestão do projeto no SERPRO e no cliente", e prossegue afirmando que "são feitas reuniões de acompanhamento do projeto com: a diretoria, os gerentes seniors representados pelos superintendentes das unidades do SERPRO envolvidas com o SOTN, os lideres dos subprojetos e os níveis estratégico e operacional do cliente". Um dos entrevistados, classificado no segundo grupo de entrevistados, criticou, inclusive, a quantidade de informação "há uma quantidade enorme de relatórios, planilhas e posicionamentos". Para um dos entrevistados classificado no segundo grupo de entrevistados "o SOTN foi o primeiro projeto do SERPRO a seguir o PSGP, criando EAP, a documentação do projeto e utilizando a ferramenta e-Car". As informações sobre a EAP e a documentação do projeto podem ser comprovadas pelo Plano de Projeto do SOTN, onde se pode 
encontrar a Estrutura Analítica do Projeto (EAP), o cronograma do projeto e outras informações sobre o projeto. A informação sobre a utilização do e-Car pode ser confirmada acessando o Sistema para Controle, Acompanhamento e Avaliação de Resultados (e-Car), principal ferramenta do SERPRO utilizada na gestão de projetos e ações empresariais pelos diversos níveis hierárquicos, principalmente pelos níveis estratégicos.

Pode-se observar, assim, que o projeto SOTN atende aos princípios de accountability, confirmando a presença deste atributo no caso sob análise.

\subsubsection{TRANSFERIBILIDADE}

A criação de condições e tecnologias que pudessem ser aproveitadas por outras áreas da Empresa pode ser confirmada principalmente pelas seguintes soluções geradas ou melhoradas pelo projeto SOTN:

- Solução de gerenciamento de serviços

Busca garantir a disponibilidade do serviço SOTN, de modo reativo e pró-ativo, com ações tempestivas. Para tanto, é realizada a monitoração por meio de ferramentas de gerenciamento, de uma estrutura em árvore de serviços, da correlação dos recursos envolvidos, das regras de propagação de eventos e dos indicadores de níveis de serviço acordados;

- Processo de execução de testes

Documenta o conjunto de testes de validação de tecnologia e arquitetura do SOTN, incluindo o planejamento, projeto, implementação, análise e o resultado da execução dos testes e um parecer conclusivo sobre as tecnologias utilizadas para construção e produção/manutenção do sistema Piloto do SOTN;

- Processo de gerenciamento de projetos

Conjunto de processos que compõem o macroprocesso de gerenciamento de projetos do SERPRO que foi desenvolvido tendo como base as melhores práticas recomendadas pelo Guia PMBOK® Conjunto de Conhecimentos em Gerenciamento de Projetos;

- Topologia com soluções de replicação e de múltiplos ambientes 
A topologia de produção foi definida a partir dos requisitos de alta disponibilidade e de robustez a falhas. Para a produção de serviços foram definidos três ambientes de produção: principal, backup e contingência. A replicação de dados é realizada em tempo real entre os ambientes de produção principal e backup e o ambiente de produção de contingência.

Para um dos responsáveis pela interação com o cliente e com diversas áreas do SERPRO com o objetivo de implantar o sistema Piloto do SOTN, a topologia, com soluções como a de replicação e de múltiplos ambientes, e a solução de gerenciamento de serviços podem ser utilizada por outras áreas da empresa. Segundo este entrevistado:

Podem ser aproveitadas por outras áreas da Empresa a topologia com soluções como a de replicação e de múltiplos ambientes e o gerenciamento de serviços, que poderia ser utilizada em solução semelhante principalmente em serviços de missão crítica.

A topologia e gerenciamento de serviços estão descritos no documento SSP05 (SERPRO, 2009h).

Um entrevistado, classificado no primeiro grupo de entrevistados, acrescentou o processo de execução de testes e o processo de gerenciamento de projetos. Segundo este entrevistado, "podem ser utilizados por outras áreas da Empresa o processo de teste desenvolvido para o SOTN, com várias ferramentas, uma documentação completa incluindo as comprovações, e a gestão de projetos que foi aprimorada no projeto SOTN". O processo de execução de teste, conforme citado anteriormente, está descrito no documento SSP12 (SERPRO, 2008) e o processo de gestão de projeto está descrito no PSGP (SERPRO, 2009b).

Outro entrevistado, classificado no segundo grupo de entrevistados, confirmou a importância do processo de gerenciamento de projeto aprimorado pelo projeto SOTN "a própria experiência na utilização das técnicas e ferramentas de gestão de projetos certamente será aproveitada em outras áreas da Empresa, já com solução para a maioria dos problemas enfrentados, pois estes não serão mais inéditos".

Dos seis entrevistados que responderam a questão "O projeto SOTN criou condições e tecnologias que pudessem ser aproveitadas por outras áreas da Empresa?", quatro consideram que a solução de gerenciamento de serviços pode ser 
aproveitada em outras áreas da Empresa. Um dos entrevistados acredita que "a solução de serviços é a que as outras áreas querem de mais imediato".

De acordo com a pesquisa documental e as entrevistas pode-se afirmar, portanto, que o projeto SOTN atende a esta característica/atributo, o que demonstra seu potencial de disseminação para outras áreas da Empresa.

\subsubsection{AMPLIAÇÃO DO NÚMERO DE BENEFICIÁRIOS}

Os impactos para o público-alvo principal podem ser observados nos benefícios gerados para o cliente e nas competências que foram adquiridas pelos recursos humanos do SERPRO envolvidos com o projeto.

Dois dos entrevistados, um deles classificado no primeiro grupo de entrevistados e o outro no segundo grupo de entrevistados, identificaram como benefício para o cliente "possibilitar que o Tesouro se comunique diretamente com todas as instituições financeiras integrantes do STR" e um deles, o entrevistado classificado no primeiro grupo de entrevistados, completou "atualmente esta comunicação é feita através do Banco Central". Esta afirmação está em concordância com o item 2.3 deste estudo. Outro entrevistado comentou sobre a plataforma de gerenciamento que permitirá ao Tesouro Nacional a visualização das operações realizadas, e que não é possível de ser obtida com a solução atual.

Os entrevistados comentaram sobre as competências adquiridas pelos empregados do SERPRO envolvidos com o projeto SOTN. Para o entrevistado pertencente ao primeiro grupo de entrevistados "foram adquiridas competências técnicas, tecnológicas, administrativas, do próprio negócio, pois é um negócio novo até para o próprio cliente". Um dos responsáveis pela interação com o cliente e com diversas áreas do SERPRO com o objetivo de implantar o sistema Piloto do SOTN detalha mais os ganhos com o conhecimento tecnológicos "ocorreram em várias áreas como Banco Dados que teve que aprender a utilizar uma nova tecnologia e assim ocorreu com o JBoss, Cluster, MQ, Safeguard, Central de Monitoração". O uso destas tecnologias está descrito no Documento de Solução da Arquitetura - DAS do Piloto SOTN (SSP04) que apresenta o detalhamento técnico da arquitetura e das tecnologias adotadas para todo o Ambiente de Produção utilizado pelo SOTN (SERPRO, 2009g). Para um dos entrevistados "as competências na área do gerenciamento de serviços, estas são novas competências e representam um diferencial na prestação do serviço". O gerenciamento de serviços está descrito no documento SSP05 (SERPRO, 2009h). 
Um dos entrevistados acrescentou "estudar uma normatização do Banco Central que não foi especificada pelo cliente, e a partir dela, projetar uma arquitetura exclusiva e integrada".

Houve divergência entre os entrevistados em relação ao impacto para outros atores que não o público-alvo e na forma como estes teriam sido sensibilizados. Para um dos entrevistados "estas competências foram distribuídas mais pela longa duração do projeto do que por uma ação orquestrada". Um dos entrevistados disse que "o conhecimento foi distribuído apenas para aquelas que estão envolvidas com o SOTN e não para a Empresa como um todo" e este entrevistado acredita, ainda, que outros projetos passarão pelas mesmas dificuldades encontradas pelo SOTN. Um dos entrevistados considera que "o conhecimento foi bem distribuído, apesar de algumas pessoas conhecerem mais do que outras, o que é inerente à natureza humana". Outro entrevistado, classificado no primeiro grupo de entrevistados, afirma que

\begin{abstract}
O conhecimento foi distribuído em função de mais de 100 pessoas terem passado pelo projeto nestes quase 4 anos de projeto. Hoje, o projeto tem em torno de 50 pessoas diretamente envolvidas. As pessoas que, até então, se envolveram com o projeto tem bom conhecimento da solução, principalmente em função dos testes que envolvem e envolveram todas as áreas participantes do projeto Quanto à gerência de serviço, apesar de todas as áreas envolvidas com o SOTN conhecerem esta solução, o conhecimento ainda tem que ser muito disseminado pelo SERPRO. Em relação aos testes, somente uma equipe em Fortaleza tem condições de conduzir o processo teste elaborado para o SOTN.
\end{abstract}

Muito embora haja discordância entre os entrevistados sobre a transferência de conhecimento, de acordo com o item 4.2.1 os processos corporativos foram adequados em função do projeto SOTN. Esta afirmação remete ao fato de que o projeto SOTN gerou e/ou gerará impactos não só para o público-alvo principal, mas para toda a organização. O que não houve foi uma ação institucionalizada para distribuir todas as competências que foram adquiridas no projeto SOTN para a Empresa.

Nossa análise permite então afirmar que o projeto SOTN atende parcialmente esta característica/atributo. Atende em relação a gerar impactos para o público-alvo principal, mas atende parcialmente quando se refere a outros públicos, a outros atores. 


\title{
4.1.5. INCORPORAÇÃO DE TECNOLOGIAS FACILITADORAS DA AÇÃO PÚBLICA
}

Segundo o documento SSP05, "A infra-estrutura de produção foi definida a partir dos requisitos de alta disponibilidade e de robustez a falhas, exigidos pelo Banco Central aos participantes da Rede do Sistema Financeiro Nacional" (SERPRO, 2009h). Está necessidade estimulou o uso de novas tecnologias que facilitam e tornam mais eficazes as ações públicas. Outro entrevistado, classificado no segundo grupo de entrevistados, reforça o que está documentado quando diz que

\begin{abstract}
A introdução de novas tecnologias foi estimulada pelo SOTN possuir características inéditas em relação a todos os sistemas desenvolvidos pelo SERPRO, como operação em tempo real, nível de serviço extremamente rigoroso, monitoração rigorosa do serviço, necessidade de ambiente de contingência on-line, tempestividade no tratamento e solução de problemas.
\end{abstract}

E complementa "teve que ser construída uma solução diferenciada".

As principais novas tecnologias introduzidas pelo SOTN que facilitam e permitem ações públicas mais eficazes são: redundância e contingência com replicação em tempo real por hardware e software e solução de gerenciamento de serviços. Um dos entrevistados pertencente ao primeiro grupo de entrevistados informa que "por se exigir uma solução robusta de alta disponibilidade todos os recursos são redundantes e exclusivos e com solução inovadora de replicação por hardware e software para o ambiente de contingência". O responsável pela interação com o cliente e com diversas áreas do SERPRO com o objetivo de implantar a solução de gerenciamento de serviços diz que "a solução de gerenciamento de serviços dota o cliente de uma plataforma de gerenciamento que permite a visualização das operações realizadas".

A solução de redundância e contingência com replicação em tempo real por hardware e software está descrita no documento SSP04 (SERPRO, 2009g). A solução de gerenciamento de serviços está descrita no documento SSP05 (SERPRO, 2009h) e foi especificada no Projeto Básico e na Proposta Comercial para a produção do SOTN.

De acordo com a pesquisa documental e as entrevistas pode-se afirmar que o projeto SOTN atende a esta característica/atributo, ampliando seu impacto na própria empresa. 


\subsubsection{VISÃO GERAL DO POTENCIAL DE INOVAÇÃO DO PROJETO SOTN}

O Quadro 8 permite uma visão geral do potencial de inovação do projeto SOTN.

\begin{tabular}{|l|l|l|}
\hline Características/Atributos & Descrição & $\begin{array}{l}\text { É atendida pelo } \\
\text { projeto SOTN? }\end{array}$ \\
\hline $\begin{array}{l}\text { Introdução de mudanças, } \\
\text { qualitativas e quantitativas, } \\
\text { em relação a práticas } \\
\text { anteriores }\end{array}$ & $\begin{array}{l}\text { Introduzir novos modos ou modelos de provisão de } \\
\text { bens erviços, ser capaz de mudar hábitos ou } \\
\text { costumes de trabalho, desenvolver produtos e e } \\
\text { serviços, tanto novos, quanto renovar antigos }\end{array}$ & Sim \\
\hline Accountability & $\begin{array}{l}\text { Ter suas contas e seu funcionamento apresentados } \\
\text { de forma clara, objetiva e transparente aos seus } \\
\text { apoiadores e à sociedade em geral, com prestações } \\
\text { regulares de contas }\end{array}$ & Sim \\
\hline Transferibilidade & $\begin{array}{l}\text { Criar condições e tecnologias transferíveis e e } \\
\text { aproveitáveis em outras áreas, contextos, } \\
\text { administrações e regioses }\end{array}$ & Sim \\
\hline $\begin{array}{l}\text { Ampliação do número de } \\
\text { beneficiários }\end{array}$ & $\begin{array}{l}\text { Gerar impactos não apenas para o público-alvo } \\
\text { principal, mas também sobre outros cidadãos e e } \\
\text { segmentos localizados ao redor, passíveis de serem } \\
\text { sensibilizados e beneficiados de forma indireta }\end{array}$ & Parcialmente \\
\hline $\begin{array}{l}\text { Incorporação de tecnologias } \\
\text { facilitadoras da ação pública }\end{array}$ & $\begin{array}{l}\text { Estimular a introdução de novas tecnologias (como } \\
\text { internet, sistemas de acompanhamento informatizado } \\
\text { e outros) que facilitem e tornem mais eficaz a ação } \\
\text { pública, rompendo ou quebrando paradigmas de ação } \\
\text { mais antigos e menos eficazes }\end{array}$ & Sim \\
\hline
\end{tabular}

Quadro 8 - Atendimento das características/atributos pelo projeto SOTN

Fonte: Adaptado de Klering e Andrade (2006, p. 92-95)

Pode-se observar a partir do Quadro 8 que o potencial de inovação do projeto SOTN atende às características/atributos: introdução de mudanças, qualitativas e quantitativas, em relação a práticas anteriores; accountability; transferibilidade; e incorporação de tecnologias facilitadoras da ação pública, e atende parcialmente a característica/atributo.

\subsection{INOVAÇÃO TECNOLÓGICA EM SERVIÇOS PARA O SOTN}

A partir do modelo do ciclo reverso do produto de Barras (1986), pode-se enquadrar os resultados do processo de inovação analisado na SOTN tanto em melhoria da qualidade quanto em novos serviços.

A melhoria da qualidade pode ser justificada pelo fato deste serviço vir a substituir um serviço já existente, implementando uma infra-estrutura, onde, segundo um dos entrevistados, "grande parte das tecnologias utilizadas foram novidades", o 
responsável pela interação com o cliente e com diversas áreas do SERPRO com o objetivo de implantar a solução de gerenciamento de serviços, complementa que

\begin{abstract}
As principais novidades tecnológicas foram: a solução de gerenciamento de serviços, a solução de replicação dos dados, o modelo de desacoplamento entre as camadas utilizado pelo software, a alta disponibilidade e a robustez da solução.
\end{abstract}

Um dos responsáveis pela interação com o cliente e com diversas áreas do SERPRO com o objetivo de implantar o sistema Piloto do SOTN inclui, ainda, "a solução de redundância e de contingência". Um dos entrevistados, classificado no segundo grupo de entrevistados, enfatizou que "o SOTN busca a eficácia e não a eficiência", enquanto outro entrevistado, classificado no primeiro grupo de entrevistados, afirma que

O Tesouro Nacional vai passar a cumprir o seu papel com plena qualidade. A solução é altamente parametrizada, permitindo ao Tesouro condições de se adequar às evoluções do SPB, sem necessidade de alterar a aplicação.

E acrescenta que "a solução construída é de fácil integração com outros sistemas".

Os novos serviços podem ser justificados por representarem, segundo um dos entrevistados classificado no terceiro grupo de entrevistados "uma mudança muito radical na solução hoje existente". Para o entrevistado pertencente ao primeiro grupo de entrevistados

\footnotetext{
O SERPRO construiu: uma nova linha de negócio que é a forma de gerenciar serviços implementada para o SOTN; e uma solução de mensageria que pode ser utilizada em outros serviços baseados em troca de mensagens e que pode ser bastante explorada pelo SERPRO e, até pelo Tesouro Nacional As principais novidades tecnológicas foram: a solução de gerenciamento de serviços, a solução de replicação dos dados, o modelo de desacoplamento entre as camadas utilizado pelo software, a alta disponibilidade e a robustez da solução.
}

O resultado apresentado permite comprovar o enquadramento do SOTN nas segunda e terceira fases do ciclo reverso do produto que são denominadas neste estudo por melhoria da qualidade e novos serviços respectivamente, quando demonstra que três entrevistados acreditam que o SOTN pode ser melhor enquadrado 
como melhoria da qualidade, outros três entrevistados acreditam que o SOTN pode ser melhor enquadrado como novos serviços e um outro entrevistados acredita que está igualmente enquadrado na melhoria da qualidade e em novos serviços.

O SOTN em termos de especificação não pode ser entendido como inovador. Como um dos entrevistados, classificado no segundo grupo de entrevistados, diz "o SOTN está circunscrito às demandas e ao que foi pactuado com o Tesouro", em outras palavras, ele atende ao que foi demandado pelo cliente Secretaria do Tesouro Nacional (STN). Porém as soluções que fazem parte do serviço SOTN e que foram criadas para atender aos requisitos do Banco Central e do Tesouro Nacional, estas sim, são inovadoras. Uma das principais soluções que confirmam esta afirmação, e que permite enquadrar o SOTN tanto em melhoria da qualidade quanto em novos serviços, e que foi citada por todos os entrevistados é o gerenciamento de serviços. Segundo um dos entrevistados classificado no segundo grupo de entrevistados

\footnotetext{
O principal benefício da solução SOTN foi de o cliente passar a ter uma forma de gerenciar o serviço através de uma plataforma de gerenciamento que permite a visualização das operações realizadas, em tempo real, e que não é possível ser obtida com a solução atual.
}

A solução anterior ao STN, O SPB mainframe, não dispunha de uma plataforma de gerenciamento e o SIAFI era o único instrumento para visibilidade das operações realizadas. 


\section{CONCLUSÕES}

Em relação ao potencial de inovação do projeto SOTN, pode-se observar que as características/atributos de práticas inovadoras para o setor público identificadas por Klering e Andrade (2006), apresentadas no Quadro 2, ou um subconjunto delas, como as apresentadas no Quadro 6, são adequadas para avaliar o potencial de inovação de um projeto que implementa uma solução de Tecnologia da Informação e Comunicação (TIC) baseada em sistemas de informação, como é o caso da integração da Conta Única com o Sistema de Pagamentos Brasileiro (SPB). Conforme a análise dos resultados, o potencial de inovação do projeto SOTN atende às características/atributos: introdução de mudanças, qualitativas e quantitativas, em relação a práticas anteriores; accountability; transferibilidade; e incorporação de tecnologias facilitadoras da ação pública, e atende parcialmente à característica/atributo: ampliação do número de beneficiários. Entende-se que este resultado parcial foi motivado, principalmente, pela falta de uma ação institucionalizada que permitisse ao projeto gerar impactos a outros públicos que não o público-alvo principal. A maior parte do conhecimento técnico e gerencial adquirido no projeto ficou restrito aos recursos humanos diretamente envolvidos com o projeto.

Em relação à inovação tecnológica em serviços para o SOTN, pode-se observar que o modelo do ciclo reverso do produto proposto por Barras (1986) pode ser utilizado para situar a inovação em uma solução de TIC baseada em sistemas de informação, como é o caso da integração da Conta Única com o SPB. Apesar de a análise dos resultados enquadrar o SOTN nas segunda e terceira fases do ciclo reverso do produto, pode-se observar que o SOTN migrou da segunda para a terceira fase, pois as soluções que foram criadas para melhorar a atual solução que integra a Conta Única com o SPB, principalmente como a solução de gerenciamento de serviços, tornaram-se robustas e abriram espaço para a criação de novos negócios ou de melhoria radical nos serviços existentes. Assim, como o modelo de Barras (1986) corresponde ao ciclo de vida da inovação em serviços, a mudança de uma fase para outra é viável e demonstra a evolução da inovação nesta solução.

A partir das duas categorias apresentadas acima, conclui-se que a solução de TIC responsável pela integração da Conta Única com o SPB é um serviço inovador.

Propõem-se dois estudos futuros utilizando os modelos de análise construídos, neste estudo, para identificar se a solução de TIC responsável pela 
integração da Conta Única com o SPB pode ser considerada um serviço inovador, com a finalidade de validar estes modelos: um estudo que avalie a inovação tecnológica para outros serviços do SERPRO e outro estudo, que meça o potencial de inovação em outros projetos do SERPRO. Para este segundo estudo é necessário reavaliar as características/atributos a serem utilizadas. 


\section{REFERÊNCIAS}

ALBUQUERQUE, C.; MEDEIROS, M.; FEIJÓ, P.H. Gestão de finanças públicas. 2.ed. Brasília: [s.n.], 2008.

BARRAS, R. Towards a theory of innovation in services. Research Policy, v.15, p.161-173, 1986.

BERNARDES, R.; KALLUP, A. A emergência dos serviços intensivos em conhecimento no Brasil. In: BERNARDES, R.; ANDREASSI, T. (Org.). Inovação em serviços intensivos em conhecimento. São Paulo: Saraiva, 2007. p.117-155.

BRESSER PEREIRA, L. C. Gestão do setor público: estratégia e estruturas para um novo Estado. In: BRESSER PEREIRA, L. C.; SPINK, P. (Org.). Reforma do estado e administração pública gerencial. 6.ed. Rio de Janeiro: FGV, 2005. p.21-38.

CASTRO, D. P.; GARCIA, L. M. Reformulação das finanças públicas no Brasil. In: 2008.cap.3.

Contabilidade pública no Governo Federal. 2.ed. São Paulo: Atlas,

FARAH, M. F. S. Inovação e o governo local no Brasil contemporâneo. In: JACOBI, P.; PINHO, J. A. (Org.). Inovação no campo da gestão pública local: novos desafios, novos patamares. Rio de Janeiro: FGV, 2006. p. 41-75.

FERREIRA, A. B. H. Novo dicionário da língua portuguesa. 2.ed. Rio de Janeiro: Nova Fronteira, 1986. p. 949.

FREIRE, C. T. Um estudo sobre os serviços intensivos em conhecimento no Brasil. In: NEGRI, J. A.; KUBOTA, L. C. (Org.). Estrutura e dinâmica do setor de serviços no Brasil. Brasília: IPEA, 2006. p.107-131.

GALLOUJ, F. Economia da inovação: um balanço dos debates recentes. In: BERNARDES, R.; ANDREASSI, T. (Org.). Inovação em serviços intensivos em conhecimento. São Paulo: Saraiva, 2007. p.3-27.

GASKELL, G. Entrevistas individuais e grupais. In: BAUER, M. W.; GASKELL, G. (Org.). Pesquisa qualitativa com texto, imagem e som: um manual prático. Petrópolis: Vozes, 2002. p.64-89. 
GODOY, A. S. Introdução à pesquisa qualitativa e suas possibilidade. Revista de Administração de Empresas, São Paulo, V.35, n.2, p.57-63, mar./abr.1995.

HAMDANI, D.; FOSSEY, M. F. Serviços, criação de conhecimento e inovação. In: BERNARDES, R.; ANDREASSI, T. (Org.). Inovação em serviços intensivos em conhecimento. São Paulo: Saraiva, 2007. p.29-55.

INSTITUTO BRASILEIRO DE GEOGRAFIA E ESTATÍSTICA. Contas anuais trimestrais 2008. Disponível em <HTTP://www.ibge.gov.br>. Acesso em: 05 jan.2009.

KETTL, D. F. A revolução global: reforma da administração do setor público. In: BRESSER PEREIRA, L. C.; SPINK, P. (Org.). Reforma do estado e administração pública gerencial. 6.ed. Rio de Janeiro: FGV, 2005. p.75-121.

KLERING, L. R.; ANDRADE, J. A. Inovação na gestão pública: compreensão do conceito a partir da teoria e da prática. In: JACOBI, P.; PINHO, J. A. (Org.). Inovação no campo da gestão pública local: novos desafios, novos patamares. Rio de Janeiro: FGV, 2006. p.77-97.

KON, A. Serviços de conhecimento: uma agenda para a indução do desenvolvimento econômico. In: BERNARDES, R.; ANDREASSI, T. (Org.). Inovação em serviços intensivos em conhecimento. São Paulo: Saraiva, 2007. p.79-115.

KUBOTA, L. C. A inovação Tecnológica das firmas de serviços no Brasil. In: NEGRI, J. A.; KUBOTA, L. C. (Org.). Estrutura e dinâmica do setor de serviços no Brasil. Brasília: IPEA, 2006. p.35-72.

MINISTÉRIO DO PLANEJAMENTO, ORÇAMENTO E GESTÃO. Concurso Inovação na gestão pública federal. Disponível em <http://inovacao.enap.gov.br>. Acesso em: 01 mai.2009.

MINISTÉRIO DO PLANEJAMENTO, ORÇAMENTO E GESTÃO. Estratégia geral de TI 2008. Dez.2008.

PAVITT, K. Sectoral patterns of technical change: towards taxonomy and a theory, Research Policy, v.13, p.343-373, 1984. 
SERPRO. Home page. Disponível em <http://www.serpro.gov.br/instituicao/quem/>. Acesso em: 08 fev. 2009a.

. Programa SERPRO de gerenciamento de projetos - PSGP. Disponível em <http://coeep.serpronet.serpro/pgps/processos-e-projetos>. Acesso em: 13 abr.2009b.

- Processo SERPRO de desenvolvimento de soluções - PSDS. Disponível em < http://cetec.serpronet.serpro/psmds/psds > Acesso em: 13 abr.2009c. informação comunicação <http://cetet.serpronet.serpro/psgti/arquivos>. Acesso em: 13 abr.2009d.

Programa SERPRO de segurança - PSS. Disponível em <http://cetec.serpronet.serpro/segur/pss>. Acesso em: 13 abr.2009e.

Plano diretor de tecnologia da informação - PDTI. Mai.2009f. Mar.2009g.

SSP04 - Documento de solução de arquitetura - DSA do Piloto SOTN. SSP05 - Ambientes de produção da solução piloto SOTN. Abr.2009h.

SSP12 - Teste de tecnologia da solução Piloto SOTN. Jun.2008.

SPINK, P. A inovação na perspectiva dos inovadores. In: JACOBI, P.; PINHO, J. A. (Org.). Inovação no campo da gestão pública local: novos desafios, novos patamares. Rio de Janeiro: FGV, 2006. p.23-39.

TRINDADE, J. T. P.; M. SEGRE, L. M. Inovação tecnológica no setor de serviços: um enfoque no comércio varejista da grande distribuição. Boletim Técnico do Senac , v. 21, n. 3, set./dez.1995.

VARGAS, E. R. Estratégia e inovação em serviços. Organizações \& Sociedade, v.14, p.17-27, 2007. 
VARGAS, E. R.; ZAWISLAK, P. A. Inovação em serviços no paradigma da economia do aprendizado: a pertinência de uma dimensão espacial na abordagem dos sistemas de inovação. Revista de Administração Contemporânea, Rio de Janeiro, V.10, n. 1, p.139-159, 2006.

VARGAS, E. R.; ZAWISLAK, P. A. Abordagem funcional e as lógicas de inovação em serviços: desenvolvendo uma análise não-tecnicista da evolução do serviço hospitalar. Revista de Ciências da Administração, Florianópolis, V.07, n. 14, p.177-197, 2005.

YIN, R. K.; Estudo de Caso: planejamento e métodos. 3. ed. Porto Alegre: Bookman, 2005. 


\section{APÊNDICE A - Roteiro de entrevista semi-estruturada}

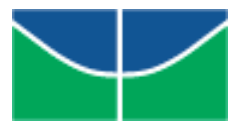

UNIVERSIDADE DE BRASÍLIA

FACULDADE DE ECONOMIA, ADMINISTRAÇÃO, CONTABILIDADE E CIÊNCIA DA INFORMAÇÃO E DOCUMENTAÇÃO - FACE PROGRAMA DE PÓS-GRADUAÇÃO EM ADMINISTRAÇÃO - PPGA

\section{BLOCO 1 - IDENTIFICAÇÃO DO ENTREVISTADO}

1.Qual é o seu nome?

2. Qual é o cargo que exerce na SUNAF?

3.Qual é o seu relacionamento com o projeto SOTN?

4. Há quanto tempo está envolvido com o projeto SOTN?

\section{BLOCO 2 - ORIGEM DO PROJETO SOTN}

5.O que motivou a criação do projeto SOTN?

6.Em sua opinião, quais são os principais benefícios a serem obtidos com a implantação do SOTN, tanto para o Cliente STN quanto para o SERPRO?

7.Em sua opinião, quais foram as principais dificuldades na implementação do projeto SOTN?

\section{BLOCO 3 - IMPLEMENTAÇÃO DO PROJETO SOTN}

8.Quais competências foram mobilizadas na execução do projeto SOTN e se essas competências tiveram condições de absorver e distribuir o conhecimento adquirido?

9.O projeto SOTN criou condições e tecnologias que pudessem ser aproveitadas por outras áreas da Empresa? 
10.Em sua opinião houve a prestação de contas e o acompanhamento do projeto? Em caso positivo, como foi realizada?

11.O projeto SOTN introduz um novo modelo de provisão de bens ou serviço para o setor público?

\section{BLOCO 4 - SOLUÇÃO TECNOLÓGICA ADOTADA NO SOTN}

12.Como se deu a opção pela infra-estrutura tecnológicas utilizada no SOTN?

13.Quais são os aspectos mais relevantes da solução adotada?

14. Quais foram as novidades tecnológicas introdução pela solução adotada?

\section{BLOCO 5 - INOVAÇÃO TECNOLÓGICA NO SERVIÇO SOTN}

15. Na melhoria da eficiência a tecnologia é aplicada na inovação incremental dos processos de prestação de serviços, com o objetivo de aprimorar a entrega dos serviços prestados, e, com isso, atingir uma redução significativa nos custos. Em sua opinião a solução SOTN se enquadra nesta definição?

16.Na melhoria da qualidade a tecnologia é aplicada para melhorar a qualidade dos serviços, ou seja, a tecnologia é direcionada para um processo inovativo mais abrangente, buscando mais eficácia do que a eficiência na entrega de serviços e mais incremento na qualidade do que a redução dos custos. Em sua opinião a solução SOTN se enquadra nesta definição?

17.Em novos serviços a tecnologia ajuda numa mudança radical dos serviços existentes ou gera novos serviços, ou seja, a ênfase na competição desloca-se para uma diferenciação do produto e o investimento em novas tecnologias torna-se predominante em relação à aplicação de capital. Em sua opinião a solução SOTN se enquadra nesta definição?

18.Em caso positivo em pelo menos duas das respostas referentes às questões 15 , 16 e 17, em qual elas você considera que a solução SOTN está mais bem enquadrada: melhoria da eficiência (questão 15); melhoria da qualidade (questão 16) ou novos serviços (questão 17)? 